AperTO - Archivio Istituzionale Open Access dell'Università di Torino

\title{
Analytical strategies for in-vivo evaluation of plant volatile emissions - A review
}

\section{This is a pre print version of the following article:}

Original Citation:

Availability:

This version is available http://hdl.handle.net/2318/1799293

since 2021-09-03T16:01:48Z

Published version:

DOI:10.1016/j.aca.2020.11.029

Terms of use:

Open Access

Anyone can freely access the full text of works made available as "Open Access". Works made available under a Creative Commons license can be used according to the terms and conditions of said license. Use of all other works requires consent of the right holder (author or publisher) if not exempted from copyright protection by the applicable law. 


\title{
In-vivo evaluation of plant volatile emissions: analytical strategies
}

\section{and biological impact}

\author{
Cecilia Cagliero" ${ }^{1, »}$, Giulia Mastellone ${ }^{1 \S}$, Arianna Marengo ${ }^{1}$, Carlo Bicchi ${ }^{1}$, Barbara \\ Sgorbini $^{1}$, Patrizia Rubiolo ${ }^{1}$ \\ ${ }^{I}$ Dipartimento di Scienza e Tecnologia del Farmaco, Università degli Studi di Torino, I-10125, Turin, \\ Italy
}

\begin{abstract}
Biogenic volatile organic compounds (BVOCs) are metabolites that are emitted by living plants and have a fundamental ecological role since they influence atmospheric chemistry, plant communication and pollinator/herbivore behaviour, and, last but not least, human activities. Over the years, several strategies have been developed, to isolate and identify them, and take advantage of their activity. The main techniques used in the plant field, for in-vivo determination, are dynamic headspace (D-HS), static headspace (S-HS) and, more recently, direct contact (DC) methods in association with gas chromatography (GC) and mass spectrometry (MS). The aim of this review is to give an insight into the in-vivo characterisation of plant volatile emissions with a focus on sampling, analysis and possible applications. A critical discussion is first reported on the features and challenges of conventional approaches and current trends to highlight their limitations and advantages. In the following, the review describes the main applications to enhance the impact of in-vivo volatilomic studies on our knowledge of plants, including the effects of abiotic (damage, flooding...) and biotic (insect feeding...) stresses compared to the behaviour of undamaged plants.
\end{abstract}


Keywords: Biogenic Volatile Organic Compounds; living plants; sampling; in-vivo analytical strategies; quantitation

List of abbreviations: BVOCs biogenic volatile organic compounds, CAR carboxen, D-HS dynamic headspace, DC-STE direct contact sorptive tape extraction, DI-SPME direct immersion SPME, DVB divinylbenzene, ESE equilibrium sorptive enrichment, GLVs green leaf volatiles, HCC high concentration capacity, HRMS nigh resolution mass spectrometry, MEMS microelectromechanical-system, MHE multiple headspace extraction, MTBE methyl tert-butyl ether, MWCNTs multi-walled carbon nanotubes, PAR photosynthetically active radiation, PTFE polytetrafluoroethylene, HIPVs herbivore-induced plant volatiles, PTR proton transfer reaction, S-HS static headspace, SBSE stir bar sorptive extraction, SESI secondary electrospray ionization source, SIDA stable isotope dilution assay, SOA secondary organic aerosol,

\footnotetext{
§ Both authors contributed equally to this work

*Corresponding author: Email: cecilia.cagliero@unito.it, Via Pietro Giuria, 9, I-10125, Torino, Italy, Tel: +39-011-6707133
} 


\section{Introduction}

All plants emit non-organic volatiles $\left(\mathrm{CO}_{2}, \mathrm{O}_{2}\right)$ during photosynthesis and respiration, but most of them also produce many biogenic volatile organic compounds (BVOCs). These volatiles (chiefly terpenoids, fatty acid degradation products, phenylpropanoids and amino acid-derived products) are produced in different plant organs (leaves, flowers, fruits, but also roots). They are stored in specialised secretory structures, such as glandular trichomes and resin ducts, and are spontaneously released by the plants, even if their emission can vary depending on specific stress conditions. These analytes play a fundamental role in the defence mechanisms against herbivores and pathogens, in the attraction of pollinators and seed dispersers, and as signals in plant-plant communication. Besides their role for the plant, BVOCs can also have important ecological relevance (they can act as precursors of tropospheric phytotoxic compounds) and, last but not least, they present a wide range of biological activities also for humans, making them a sustainable and under-exploited source of bioactive compounds [1,2].

The plant volatilome $[2,3]$, is made up of more than 1700 volatile compounds isolated from more than 90 plant families, and its study therefore requires a metabolomic approach [4]. In addition, it is important to avoid alterations to the metabolomic profile so that it can provide a true signature of the biochemical activity of the investigated biosystem. Specific in-vivo analytical strategies are required to prevent: i) the de-novo formation of compounds biosynthesised in response to any damage resulting from plant collection; ii) possible enzymemediated metabolite conversion; and iii) chemical degradation of labile metabolites [5]. Sample preparation play a fundamental role in this respect and the development of static and dynamic techniques for the headspace collection of volatiles in combination with a suitable analytical platform (mainly gas chromatography-mass spectrometry (GC-MS)) has significantly contributed to the development of dedicated analytical strategies for the in-vivo investigation of the plant volatilome, thus improving the understanding of the biosynthesis and ecology of plant BVOC compounds $[1,2]$. 
In this article, we first provide a review of the main sampling and analytical approaches developed in the last twenty years for the in-vivo analysis of plant volatiles, with emphasis on some underestimated, but crucial, features of the analytical procedure, such as quantification. The second part of this work focuses on the impact of in-vivo volatilomic studies on our knowledge of plant behaviour, examining the spontaneous emission of BVOCs in healthy plants and how the plant volatilome can be affected by different abiotic and biotic stresses.

\section{Sampling strategies}

Research of proper analytical strategies to investigate the volatile profile of plants is fundamental to the correct characterisation of their metabolism and of their relationship with the ecosystem. As most biological systems are too complex for direct analysis [6], a sample preparation procedure is in general required. For this reason, the sampling step is a crucial point in the development of an analytical method $[7,8]$.

The main challenge in the analysis of plant BVOC emissions is their complexity, in terms of the number of compounds and difference in relative abundances (as most of them are present at a trace level) [7, 9]. On account of these considerations, current efforts in volatilomics are directed towards easy, fast, sustainable and sensitive sampling methods.

\subsection{Techniques}

Conventional samples preparation methods for the analysis of plant emissions involves destructive and time-consuming approaches, such as solvent extraction and/or distillation. Moreover, harvesting single plant parts (flowers, leaves, fruits, etc.) can induce stress, and thus alter the BVOC profile $[10,11]$ On the other hand, the analysis of the living systems provides more representative BVOC emissions and reliable data, because it minimises the perturbation caused by external factors [1]. In-situ measurements should therefore be preferred, when possible, to laboratory-based experiments to avoid interference(s) on the plant natural emissions $[7,12]$ 
Of the possible approaches for the in vivo collection of volatiles, the most common is headspace (HS) sampling, i.e. the analysis of the gaseous/vapour phase in equilibrium with the plant $[1$, 13, 14]. The HS technique can be either in dynamic (D-HS) or static (S-HS) modes, depending on the instrumentation and procedures employed. It allows non-invasive sampling [1], although the enclosed system can create humidity and increases in temperature $[1,7,12]$.

A less widespread, but innovative, approach in BVOCs sampling is by direct contact between the extraction phase and the plant sample [7, 12, 15]. Its advantages also include good sensitivity for polar and semi-volatile compounds, which concurs to overcome some of the limitations of headspace sampling. Figure 1 shows an overview of the main techniques employed in BVOC sampling; they are described more in details in the following paragraphs, focusing on their advantages and limitations (Figure 2).

\subsubsection{Dynamic headspace}

The use of D-HS for plant volatile analysis dates back to the 1960s, when it was introduced by Wahlroos [16], and immediately applied by Herout to the sampling of flower volatiles [17]. DHS is nowadays one of the most heavily explored approaches in this research area $[1,14]$. As shown in Figure 1A, its success is largely due to its versatility related to the possibility to choose different trapping system and materials that enables to recover the target analytes also in function of their chemical characteristics. In detail, a controlled and inert gas flow is passed through the plant sample and directed to a trapping system, where the volatiles are concentrated [1]. The desorption of the trapped volatiles is crucial and requires intense treatments, such as solvents or heat desorption, to ensure full compound release [18]. A proper D-HS set-up requires a relatively complex equipment and the standardisation of several parameters if a reliable in-vivo sampling is to be obtained [14]. In general, the whole plant or the living part(s) under investigation are placed in an enclosure system to facilitate the isolation of the volatiles. Depending on the material, volume and technology, several types of enclosure have been employed for plant BVOC analysis, including glass/plastic chambers [18-23] and gas exchange 
cuvette systems [24-34], affording a quick monitoring of plant gaseous exchange of BVOCs, $\mathrm{CO}_{2}$ and $\mathrm{H}_{2} \mathrm{O}$,. Figure 1A shows the configuration of the two most common cuvette enclosures; large and inflatable "bags" can be used for the detection of tree-branch emissions (Figure 3A), while the "sandwich" system is commonly used for leaf analysis [1].

As mentioned above, many variables must be considered when dealing with D-HS in-vivo systems. In particular, the enclosure may change the natural plant micro-ambient, meaning that several parameters must continuously be monitored during the analysis. An equilibrium time (12-48 h) before the beginning of sampling is usually necessary to minimise and stabilise the stresses generated by confinement [25, 32, 35-39]. The incoming air is usually purified with charcoal filters to eliminate external BVOCs $[22,25,38-44]$ and the flow, which can reach 25 $\mathrm{L} \mathrm{min}^{-1}$, is controlled by a flowmeter/pump to limit water condensation and temperature increases, at the same time, avoiding losses of analytes from the trap during sampling (the socalled breakthrough effect) [38]. In this regard, Balthussen et al. developed equilibrium sorptive enrichment (ESE) to concentrate volatile compounds from matrices more susceptible to the breakthrough effect [45]. ESE is a dynamic approach where the gas flow continues until the analytes reach the equilibrium with the sorbent material (in general PDMS beds), thus assuring accurate and sensitive sampling. However, the equilibrium in ESE requires that analytes concentration is constant over the whole sampling time, and this limits its application to the invivo analysis of plants [45]. Other parameters to be considered are temperature, humidity and light $[19,25-27,29,30,33,39,43,46-50]$.

The trapping mechanism depends on the nature of the material that conditions its specific interactions with the analytes. PDMS and other inert and thermally stable sorbent polymers [18, $20,33,38,51]$, have recently been introduced in alternative to the widely used adsorption carbon-based (Carbotrap, Carbograph) and polymeric (Tenax, Porapak) materials [22, 30-32, $34-36,39,40,42-44,46,47,50,52,53]$, limiting the presence of artefacts in the final profile [14]. The trapping step is often avoided when D-HS is coupled with a PTR-ToF MS detector, 
where BVOCs are directly sent to the detector $[19,25,28,29,48]$. In D-HS-GC a preconcentration step of the analytes at the head of the GC column is generally necessary; only one application among those here quoted adopts the collection of the gaseous sample from the cuvette with a gas-tight syringe followed by the direct injection in the GC system without cryocooling at the head of the column [24].

Either laboratory or greenhouse analyses are in general preferred when monitoring volatile emissions under stress factors, mainly because of the easier handling of the stress source, such as insect feeding, mechanical damage and micro/macro nutrient supplements $[18,19,22,25$ $27,29,30,33,39,47,48,50,51]$. On the other hand, field experiments ("in-situ") are less invasive and more representative of real-world living systems, but they require to set up sampling systems (enclosure, gas tanks, pumps, traps, ...) in the open field. The general approach to investigate the correlation between BVOC production and light/temperature changes consists of placing the enclosure around tree branches at specific heights $[41,53]$.

The analysis of BVOCs from living plants with D-HS has also taken advantage from the association with solid-phase microextraction (SPME) [21, 23, 37, 54-56] (for a full description of the SPME techniques in this field, see section 2.1.2). As represented in Figure 1A, the SPME fiber is exposed to the air flow circulating in the sampling chamber. In most examples, two measurements are performed simultaneously: i) the air flow passes through the enclosure/SPME system and is directly channelled to the PTR-MS detector, and ii) the SPME device is then introduced into the GC-MS system, thus obtaining a complete matrix profiling $[23,37,54]$. The complexity of the sampling procedure means that the extraction efficiency is affected by several variables and a careful optimisation is usually needed. The type of SPME fiber (PDMS or PDMS/DVB), the time of extraction and the reproducibility of the fiber recovery $[37,55]$, are among the main variables to be optimized.

A pioneering study by Sandra and et al. on the development of an automatic dynamic sampling system via a sorption trapping is also worthy of mention [18]. The proposed approach involves 
the on-line coupling in a single apparatus of the dynamic sampling step with the thermodesorption of the PDMS packed cartridges, and then of the GC-MS analysis, after cryotrapping of the desorbed analytes. In addition, two identical sampling chambers operating in parallel have been incorporated into the system, and are consecutively analysed to monitor a reference plant and a plant submitted to different stresses.

\subsubsection{Static-headspace (S-HS)}

In S-HS, a liquid or solid sample reaches the equilibrium with its vapour phase and the target analytes are transferred to the headspace, according to their partition coefficients [14]. In the original method, the gaseous phase was manually transferred to the GC using a gas-tight syringe but, over the years, different automatic systems have been developed to improve its reliability. The term "static" implies the absence of airflow in the sampling chamber making the headspace representative of the sample emissions $[1,14,57]$ S-HS therefore provides a picture of the volatile emission very close to reality. This “one-step gas-extraction” technique has given optimal results in the investigation of plant volatiles thanks to its simplicity, versatility and ease of automation. On the other hand, the absence of analyte enrichment or accumulation systems causes a limited sensitivity. To overcome this limit, high concentration capacity HS techniques (HCC-HS) have been developed since the 1990s. These implied that analytes are accumulated from a vapour in static equilibrium or a liquid phase on a stationary phase by sorption or adsorption [14]. A successful example of HCC-HS technique is HS-SPME [58], which has widely been employed in the analysis of volatiles as it provides good sensitivity in short sampling times. As shown in Figure 1B, the SPME device includes a fiber coated with a thin film of sorbent/adsorbent, that is exposed to the headspace of the plant sample. Two main equilibria affect the analyte recovery: i) the plant/HS equilibrium, and ii) the HS/fiber accumulation equilibrium. Therefore, the nature of the fiber coating is one of the key parameters to optimize the recovery of the compounds of interest $[14,59]$. PDMS was reported as the most 
effective and inert polymer in this respect, in particular for benzenoids, terpenes and fatty acid derivatives in plant analysis [60-67]. In addition, other SPME coatings have also been applied to this field, in particular CAR/PDMS [13, 68-70], and PDMS/DVB [71-76], while a few applications use the DVB/CAR/PDMS combination because of its lower inertness, despite of its high effectiveness $[11,77]$.

The plant sample to be analysed is normally enclosed in a customised "chamber" to isolate the sample and limit external interference, as it shown in Figure 3B. In most laboratory applications, a glass container (flask, vial, bottle, cage, etc.) is used [11, 13, 61-65, 68-71, 73, $75,76]$. To avoid contamination from the container, Acaraz-Zini et al., have sampled the leaves of Eucalyptus citriodora Hook. in a silanised glass chamber and carried out daily checks to monitor possible artefact formation [73].

Extraction time is another parameter that must be carefully optimised and that depends mostly on the physicochemical characteristics of the compounds to be isolated, since the most volatile and low-molecular-weight compounds equilibrated more rapidly [60]. Extraction temperature is normally kept around $20-25^{\circ} \mathrm{C}$, since the majority of studies should be carried out at ambient temperature to obtain representative results [61-65, 68-73, 75-77]. Fernandes et al. however successfully applied higher sampling temperatures $\left(40-60^{\circ} \mathrm{C}\right)$ to monitor the volatile emissions from Pieris brassicae L. larvae fed with Brassica oleracea var. acephala DC. plant [71].

Eilers et al. developed a novel static system to monitor the volatile emissions of Taraxacum sect. ruderalia, Kirschner, Øllgaard et Štěpánek roots. This particular set-up uses a customised glass vessel in which BVOCs passively concentrate onto PDMS tubes, without using air flow [78].

\subsubsection{Direct contact}

Direct contact between the sampling device and the plant sample (see Figure 1C) is one of the most recent approaches to the in-vivo investigation of plant volatile emission. This approach 
has mainly been used for the analysis of in-vivo emissions with the well-known direct immersion (DI)-SPME technique and less with the direct contact sorptive tape extraction (DCSTE) [12].

DI-SPME is a minimally invasive, solvent-free technique in which a fiber coated with a sorbent material is directly introduced into the plant $[57,79]$. Originally developed for the analysis of environmental or clinical liquid samples, DI-SPME has also proven to be a promising method to analyze multicomponent biosystems, as it enables a more complete analyte coverage, also including also less volatile compounds i.e. difficult to transfer in the headspace [80]. However, the use of DI-SPME in complex matrices requires some precautions to avoid mechanical degradation of the fiber when introduced into the plant. To improve matrix-compatibility, specific SPME coatings have been developed over the years, including CAR/PDMS, DVB/CAR/PDMS [80] or coating with protective layers such as PDMS/DVB/PDMS [79]. Borsdorf et al., [81] have used a CAR/PDMS fiber to measure the uptake of the MTBE contaminant by a wetland plant under field and laboratory conditions. The fiber was wired to the plant stem at a specific height to facilitate the extraction. In this study, the authors observed that an in-situ analysis is preferable to avoid possible fiber damages when it is removed from the plant (and thereby loss of analytes). A similar approach was used to investigate the behaviour of different plant species treated with 1,8-cineole allelochemical solutions [82]. Sampling was by a $100 \mu \mathrm{m}$ PDMS coating and the analysis was carried out in laboratory. Both examples implied the extraction of a target compound from a specific part of the plant in contact with the fiber, without considering its distribution in the other compartments. Besides the measurement of specific chemical up-take, DI-SPME was also employed to monitor the spontaneous volatile emissions by Malus domestica Borkh. fruits. The PDMS/DV/CAR fiber was inserted into apples at different maturity stages, perpendicularly to the fruit stem [5]. A comparison with the ex-vivo procedure underlined some differences in the metabolite fingerprint, and these differences were caused by enzymatic and oxidative degradation due to 
sample preparation and harvesting. The in-vivo technique minimised the perturbations to the system and enabled to extract a profile closer to reality.

A particular in-vivo DI-SPME application has to be remarked, Chen et al. monitored the accumulation and elimination of exogenous contaminants carried by multi-walled carbon nanotubes (MWCNTs) in Brassica juncea (L.) Czern plants. This direct sampling minimally perturbed the living system and provided an accurate analysis of the kinetic processes, showing to be very promising to study plant metabolism in-vivo [83].

Sandra el al. successfully introduced DC-STE for sampling from living matrix [84, 85], in particular for the analysis of sebum on the surface of human skin [84]. DC-STE is a solventfree and easy-to-use technique consisting of a flexible thin PDMS tape that provides high analyte recoveries thanks to the wide exchange surface in contact with the sample $[12,15,85]$. Bicchi et al. [85] have illustrated the advantages of this innovative technique in the analysis of plant volatiles, nevertheless few applications to in-vivo plant sampling have been reported in the literature $[12,15,86]$. The PDMS tape is placed on the plant with a glass coverslip, which also avoids PDMS-air interactions. Analysis time is highly variable, ranging from $20 \mathrm{~min}$ to 24 $\mathrm{h}$, depending on the abundance of volatile to be studied and on their kinetics of formation $[15$, 86]. In a study concerning the Lima bean/cotton leafworm interaction (see below), Boggia et al. (Figure 3C) have shown that the production of BVOCs is time-dependent, and that, after damage, green-leaf volatiles (GLVs) related to lipoxygenase are the first to be produced, while terpenes are released later [15]. The nature and amount of BVOCs that are biosynthesised by the plant are also influenced by the sampled organ portion and depend on both the anatomy of the tissue (such as density of glandular trichomes) and the extent of the damaged area. The nature of DC-STE also enables in-vivo and in-situ topographical studies to be performed to investigate BVOC emissions from different parts of the plant simultaneously $[15,86]$. Moreover, the comparison with a conventional D-HS method has demonstrated that the DCSTE approach has higher sensitivity, together with lower matrix interference because the direct- 
sorption mechanism eliminated the plant-air interaction equilibrium, reducing the number of phases involved $[15,86]$. Last but not least, contamination from volatiles emitted by other plants is minimised in in-field experiments [12]. Similar direct contact experiments can also be carried out with with PDMS coated stir-bars (Twisters) (DC-SBSE), which however offers a lower contact surface (and thereby sensitivity) compared to PDMS tapes but they are simpler to be fixed on the vegetable surface because of the internal magnetic bars $[12,86]$.

\subsection{Quantitation: a challenging task}

When dealing with solid matrices, the quantification of the extracted analytes is one of the main challenges, especially for the volatile fraction emitted from living plants. This is mainly because of their heterogeneous and complex compositions and the multiphase equilibria that occur when the analytes are released into the HS. For these reasons, semi-quantitative analyses that only consider the (change in) chromatographic-peak areas or percent areas are mostly carried out, as shown in Figure 4A [5, 7, 11, 12, 20, 23, 39, 52, 55, 60-65, 67, 69, 71, 73-77, 81, 86]. Moreover, when dealing with HCC techniques, the different partition coefficients of the analytes towards the extraction phase(s) strongly affect their relative response and quantitative determinations. A correct quantitative determination is however fundamental to measure the real amount of volatiles emitted by plants and, thereby, its biochemical behaviour. The adoption of proper quantification approaches compensates for the influence of the matrix effect and help to obtain reliable and reproducible results. They mostly involve the use of standards or analogues of the compound(s) of interest to calibrate the response of the analytical instrument $[19,21,24,26$, $31,32,35-37,40,44,51,53,54,56,66,68,78,82]$. External calibration is less suitable for invivo quantification because of the difficulties in replicating and mimicking the dynamic conditions of a living system in a blank sample [15, 25, 27, 28, 30, 46, 53, 68]. The addition of internal standards (IS) to the original sample before analysis, is the most commonly used technique in plant BVOC quantification (Figure 4A) $[38,40,44,50,51,56,66,70,78]$. 
However, the distribution of IS within the matrix is not always homogeneous and repeatable, and the IS can physico-chemically and physically interact at the surface of the solid sample [87]. For example, Vereen et al., have investigated the insertion of an internal standard into the dynamic enclosure (a Tedlar bag) with living foliage, but did not obtain the expected results [60]. In this respect, internal standard can also be deuterium or $\mathrm{C}_{13}$ labelled derivatives (when available) of the target analyte(s), with the Stable Isotope Dilution Assay (SIDA) method, introduced by Schieberle and Grosch in 1987 for GC-MS analysis [88]. Moreno-Martin et al. have combined the use of isotope analogues as an IS with the standard in-fiber procedure [89] to quantify the volatile selenium derivatives released from different plants. The IS is loaded into the SPME coating and its isotopic nature assures similar characteristics to those of the target compounds, without being included in the sample [70], but making it easy to be discriminated by MS in both single or total ion modes. Multiple HS extraction (MHE) is another interesting quantitation technique especially reliable for in-equilibrium systems that can also be applied to HS-SPME. It consists in the consecutive extractions of the same sample, and the peak area sum of a suitable number of extractions enables to extrapolate the total area corresponding to the total amount of the analyte in the sample [87]. One of the possible limitations of this technique, when used on living plants, is that some BVOCs are continuously released into the HS by the plant or they are produced only after a local damage thus affecting their reliable quantitation. Nevertheless, this approach has been successfully used to determine BVOCs from Pelargonium $\times$ hortorum L.H. Bailey leaves quantitatively [13].

\section{Overview of analytical platforms}

After sampling, the next fundamental step for the characterisation of the volatile profile of a plant sample is its analysis with the adoption of an appropriate analytical platform. When BVOCs are retained in a trapping system, two approaches to desorb the analytes can be adopted:

i) solvent back-extraction (mainly with carbon disulfide, methylene chloride, hexane or 
dichloromethane) $[20,38,40,44,50-52]$ and ii) thermal treatment $[15,32-34,37,42,43,53$, $55,61,68,75,86]$. Organic solvents can easily desorb the BVOCs from the trapping material, however, this approach often require long extraction times and/or large solvent volume thus affecting the enrichment factors obtained with sampling, and it is not environmentally friendly. Thermo-desorption has to be preferred because it assures higher sensitivity and avoids the use of harmful organic solvents, provided that the investigated BVOCs are not thermolabile and artefacts are not formed [18].

Of the analytical platforms used to analyse the volatiles released from living plants, gas chromatography in combination with both mass spectrometry and flame ionisation detection (GC-MS/FID) is the most popular technique (see Tables 1 and 2 and Figure 4B) [14]. The FID/MS detection combination is complementary being MS usually necessary for a correct identification of the specific BVOCs, while FID detector can be advantageous for the quantification of both all and/or specific components or markers (sometimes expressed as total organic carbon) emitted by the plant $[21,22,27,31,32,35,36,46,52,76]$.

Conventional GC stationary phases based on polydimethylsiloxane (PDMS) and polyethylene glycol (PEG) are commonly used but other stationary phases with different selectivities have also been adopted to separate pairs or groups of challenging compounds and/or to obtain more specific information. In particular, Yassaa et al. applied a cyclodextrin-based stationary phase to separate the enantiomers of monoterpenes emitted in-vivo by several plant species $[52,55]$, while Risticevic et al., have used an ionic liquid-based stationary phase for the separation of as many analytes as possible from the metabolome of apple by GC-ToF-MS [5].

Proton-transfer-reaction MS (PTR-MS) has proven to be a valid system complementary to GCMS for the online monitoring of the volatiles emitted by living plants, and (often) not requiring specific sampling treatments [9, 19, 23, 25, 28-30, 33, 37, 47, 48, 54]. PTR ionization is based on the proton transfer processes from protonate water $\left(\mathrm{H}_{3} \mathrm{O}^{+}\right)$, which selectively reacts with most BVOCs with a non-dissociative proton transfer. Only compounds with proton affinities 
higher than that of water are ionised and detected by the MS spectrometer (for a full description of the technique see Ref. [25]). GC-MS analyses are in general time-consuming and therefore they do not allow to monitor dynamic changes in volatile emissions, while PTR-MS ensures rapid and on-line measurement of trace BVOCs belonging to different chemical groups [30, 47]. This characteristic has therefore made PTR-MS platforms highly used to monitor the variations in BVOC emissions in plants subjected to abiotic and biotic stress, as shown in Table 2 and Figure 4B. GC-MS is however still needed to confirm the volatile identity. One of the advantages of PTR-MS is the direct sample transfer that channels directly the sample into the detector (on-line analysis) [9]. In fact, several authors refrigerate the extraction device in the time-frame between sampling and GC-MS analysis to prevent degradation or loss of the analytes $[37,43,44,53,73,81]$. At the same time, GC-MS requires a solvent/thermal treatment to release the volatiles from the trapping material with the concrete risk of artefact formation or irreversible adsorption (Carbonblack or Carbotrap).

The combination of GC-MS and PTR-MS platforms has received much attention in the study of BVOC in-vivo emissions, due to the complementary combination of a technique to separate and identify the volatiles with a rapid and non-invasive monitoring of emission kinetic (see Tables 1 and 2). Moreover, in two studies on live vegetation, Bouvier-Brown et al., have demonstrated the agreement of GC-MS and PTR-MS results in terms of the total amount of terpenes detected $[37,54]$. As already mentioned, S-HS-GC-MS also gives a realistic and reliable picture of the emitted volatile fraction of a plant provided that its sensitivity is compatible with the phenomenon to be investigated.

Barrios-Collado et al. applied direct infusion high-resolution mass spectrometer (HRMS) with a secondary electrospray ionization source (SESI-Orbitrap-MS) for the real-time monitoring of more than 1200 BVOCs emitted by Begonia semperflorens Link \& Otto, and validate the proposed method by characterizing some key components via tandem mass spectrometry 
(MS/MS) with the above HRMS system and comparing the results to those obtained by GCMS [49].

As mentioned above, a minimal sample perturbation is necessary to obtain an accurate picture of living plant volatile emissions. This goal can be achieved by the concurrent contribution of both the correct choice of the sampling technique (see section 2) and of the analytical platform. In this sense, portable systems enable i) to run full direct in-field analyses thanks to their miniaturized technology, ii) to save energy, and iii) to operate under normal atmospheric pressure and temperatures [39]. However, the number of applications of BVOCS plant analysis reported in literature with portable systems are relatively low because they are not always inline with the sophisticated technologies required in this field. [23, 36, 37, 39, 41, 54] (Figure 4B). McCartney et al. proved that a portable GC with a differential mobility spectrometry (DMS) detector is a valid approach for the real-time diagnostic analysis of plant infections (the device is described elsewhere, Ref. [90]). The association of D-HS with this in field-deployable platform has highlighted some differences between the BVOC profiles of healthy and Candidatus-liberibacter-asiaticus (CLA)-infected Citrus spp. [39].

Barreira et al. measured the BVOCs at the SMEAR II Forestry Field station with a portable GC-MS, which consists of a low thermal mass capillary gas chromatograph and a miniature toroidal ion trap mass analyser. The results were compared to those of an on-line PTR-MS detector and conventional GC-MS, with good agreement [23].

Bouvier-Brown et al. adopted a similar approach to compare the emission profiles of a coniferous forest, analysed using three different analytical platforms. The branch enclosure was directly connected to a PTR-MS system and a portable GC-FID for in-situ analyses, while the fraction collected with SPME fiber used for sampling was later analysed by GC-MS. Once again, good agreement was observed between the techniques also because the SPME fiber did not show losses of volatiles and the average analyte abundance with conventional GC-MS increased [37]. 
The third, and not less important, step is the data elaboration. It is important to underline that the in-vivo analysis of complex biosystem leads to a numerous and complex chemical information, which, if not properly used, makes difficult to interpret the biological phenomena. In addition, the volatilome of a plant is closely connected to several biological processes, and appropriate statistical tools have to be adopted to correlate chemical and biological information. A detailed discussion of the approaches for the elaboration of the data obtained from the in-vivo analysis of volatiles is out of the scope of the present article because it would be too extended; the topic has been in depth and critically discussed by van Dam and Poppy [91].

\section{Applications}

BVOCs are spontaneously released by healthy plants, but their amounts can vary or de-novo compounds can be biosynthesised when the living system is subjected to an induced stress (e.g. mechanical or herbivore damage, lack or excess of specific nutrients, light variations or high or low temperatures) [92] (Figure 5). This section reports a critical description of the applications of the in-vivo analysis of volatiles on undamaged plants or in presence of specific biotic or abiotic stress; the text is organized on the basis of the biological and environmental status of the investigated plants.

\subsection{Spontaneous emissions}

Several BVOCs are spontaneously biosynthesised and released by plants in the absence of induced stress. Table 1 reports the main articles dealing with the analysis of these compounds from undamaged living plants published after 2000. The main aim of these studies is to investigate either parts of, or entire plants and to collect the largest number of BVOC naturally released into the surrounding environment. Several studies investigate the overall phytochemical pattern of the species of interest $[5,13,63,64]$, often, with a special focus on the compounds responsible for the scent that may be involved in the attraction of pollinators 
(e.g., $[40,55])$. Other important researches are addressed to the investigation of compounds involved in the production of ozone or secondary organic aerosols (SOA) (e.g. $[38,55])$. The investigated plants can be grown under laboratory conditions or directly in the field and different types of volatiles can be isolated with appropriate sampling and trapping system. Moreover, the aerial parts (the whole plant or isolated parts) are those usually under investigation, with the exception of the roots analysed by Eilers et al., [50].

Several studies aimed to analyse the BVOCs that contribute to the scent of a plant $[40,62]$. The plants subjected to scent analysis belonged to the Magnoliophyta division and the sampling is usually performed on parts of the living plant, mainly the flowers. They are generally sampled using static HS-SPME from small devices (e.g. conical flasks, chambers, funnels, bottle, mostly made of glass) to gather the head space. Stashenko et al., [74] used a transparent (polyacrylic) cylinder with a side arm to support a SPME device for the analysis of living flowers from Aristolochia ringens Vahl.

Some studies compared the volatiles emitted by living plants to the related essential oil, showing, as expected, important quali-quantitative differences with the two sampling methods [61, 63-65, 67]. Flamini et al. and Maccioni et al., reported that SPME afforded to sample small and distinctive parts of the plant considered (e.g., a whole flower can be separated into parts, like the petals and sepals, the single bracts and the leaves) with results more representative of the volatiles emitted by the plant, and complementary to those of the essential oil. Some research works evaluated the chemical differences between the results of in-vivo sampling and those from excised parts $[11,20,62,69,74]$. In a study on the volatile fingerprinting of orchids [11], Manzo et al. confirmed that the results of the analysis of collected plants differs from those obtained by HS-SPME of living samples, probably in consequences of the mechanical damage caused by excision. Moreover, an analysis of in-vivo samples allowed to evaluate the temporal variations in volatile emissions [44]. Some authors integrated the in-vivo analysis of 
the volatiles responsible for flower scent with biomolecular analyses to understand their biosynthetic pathway $[40,44,62,75]$.

Another interesting application of the in-vivo analysis of plant volatiles is the investigation of BVOCs that are emitted into the atmosphere, which are potentially involved in alterations of the oxidative capacity of the troposphere due to their rapid interaction with ozone and alcohols, giving rise to specific oxidation products. These volatiles mainly included terpenoids (e.g., isoprene, monoterpenes, sesquiterpenes) that are released spontaneously by the plant. Their emission pattern is species-specific and influenced by plant phenology and environmental factors, especially temperature and photosynthetically active radiation (PAR) [24, 54]. Table 1 shows that, except some studies $[34,52]$, the majority of the plants analysed in this respect belonged to the Pynophyta division. In-vivo and in-situ experiments are important to identify the compounds really emitted into the air. A review by Ortega et al. [93] reports all variables that should be considered for experiments on this topic and provides useful information on techniques and devices, taking into account that these species are usually large trees, whose sampling is often difficult and requires specific adaptations [94]. The review is integrated by a complementary experimental paper on the analysis of BVOCs from different plant species. The most adopted sampling technique is D-HS which provides more realistic results since the S-HS results in no air flow and therefore the results can be affected by unstable $\mathrm{CO}_{2}$ concentration and temperature increase [94]. The enclosures used in the selected works were cuvettes or bags made of different materials (e.g., Teflon, acrylic plastic with a quartz glass cover, PTFE, Tedlar). Contrary the aforementioned experiments on the analysis of small plant parts, glass is usually avoided because its weight and fragility makes its use difficult when building large enclosures and when performing in-field experiments [94]. The investigated plant parts are usually branches [32, 34, 36-38, 54, 55]. Baker et al. performed an analysis of a whole tree with a large 100 L Tedlar bag [21], while Berreira et al. used a soil chamber for the analysis of the 
forest floor, and to monitor the BVOCs emitted not only by the forest trees, but also by the understory vegetation [23].

\subsection{Emissions under stress or changes in environmental factors}

The importance of investigating and monitoring the BVOCs emitted by plants in response to stressors or changes in environmental factors is supported by the high number of studies published in the literature on this topic (see Table 2). This is related to the great influence that these volatiles exert on atmospheric chemistry (and thereby on all living systems), neighbouring

plants, pollinators and herbivores [30]. Several stresses can affect the volatile pattern released by living plants and/or induce de-novo emissions. Stresses are usually classified as abiotic (mechanical wounding, environmental factors variation...) and biotic (herbivore, pathogen attack).

Light and temperature variations are the main environmental factors influencing BVOC emission rates in living plants [95]. Monitoring and analysis of these emissions are frequently associated to specific algorithms to predict/estimate the dependence of BVOCs to light and temperature variations [96]. These models however exclude other important factors (e.g., physiological growth) that may influence volatile emission in relation to seasonal light and temperature changes [36], however some studies reported a good agreement between the results of field analyses and algorithm estimations [31, 46, 53],

In general, these measures are carried out in a forest and plants are monitored during the summer-autumn period $[27,31,35-37,43,46,53]$ or in a laboratory/greenhouse $[22,27,76$, 97]. The general trend shows an increase of terpene emissions during summer, followed by a reduction in the autumn $[36,46]$. In particular, some volatiles are comparably influenced by temperature and light [35], while others give different responses to these parameters [27, 31, 42], or even, the emission profile is species-specific [43]. 
Environmental conditions other than light/dark experiments have been investigated. Holzinger et al. simulated a flooding by covering the topsoil of a monitored plant with tap water and registered an increase in the emissions of ethanol and acetaldehyde, i.e. volatiles usually associated with anoxic conditions [25]. Beauchamp et al exposed a Nicotiana tabacum L. plant to $\mathrm{O}_{3}$ flow under lamp illumination to stimulate stomata opening, since $\mathrm{O}_{3}$ exposure is a good model practice to induce stress responses in plants. The results indicated that the response of the plants to $\mathrm{O}_{3}$ stress is highly variable and it can be influenced by other environmental variations [19].

The production of BVOCs by plants is also related to their ability of phytovolatilisation, i.e. to take elements from the soil and transform them in volatile species. This phenomenon is in particular important for the degradation of toxic compounds in polluted sites (phytoremediation). Meija et al. and Moreno-Martin et al. in two separate studies investigated the phytoremediation to selenium (typical of arid regions and released into the environment by industrial activities) by suppling the plants with Se-enriched hydroponic solutions; the result was that several Se-volatile species were detected in the headspace of the treated plants $[68$, 70]. Kreuzwieser et al., studied the variations of the BVOC profiles depending on the plant nutrient composition by suppling a Venus flytrap plant (Dionaea muscipula J. Ellis) with insect powder to understand whether the emission of specific BVOCs released to attract the pray, was affected by the plant's state of nutrition. Although the feeding changed the BVOC emission, the attraction of the insects was not influenced [33].

Many external substances can be absorbed and accumulated by plants, and some of these are volatile or can be chemically transformed into volatile compounds; their monitoring is important in view of their possible impact on humans and the environment. In this context, macrophyte plants present an extensive aerenchyma where volatile pollutants and toxic derivates can concentrate [81]. On the other hand, the in-vivo allelochemical uptake is also 
worthy to be evaluated since it can alter the volatile emission of plants [82]. DI-SPME (see section 2.1.3) proved to be a suitable technique for these investigations.

As previously reported, the volatile patterns of plants can also be modified by anoxic conditions, causing an increase in ethanol and acetaldehyde emissions [28, 29]. The use of online high resolution trace gas detectors (PTR-ToF-MS and laser photoacoustic) enabled to monitor the BVOC variation during anaerobic (dark chamber and $\mathrm{N}_{2}$ flow) and post-anaerobic conditions [28].

The ability of plants to biosynthesise a variety of volatiles to defend it against herbivore attack is widely known and studied [92]. These herbivore-induced plant volatiles (HIPVs) are emitted after herbivore damage and act both as a direct defence, and as attractant for the natural enemies of predator herbivores (indirect protection). This defensive system involves the activation of complex mechanisms, including gene expression, the triggering of enzymes and the mediation of specific hormones, such as jasmonic acid $[47,71]$. One of the most interesting aspect is that the release of BVOCs is not strictly limited to the region object of the attack, but it is a systemic response, especially when reproductive parts (e.g., flowers, seeds) are affected [30, 51, 92].

The first in-vivo studies on this topic were run by inflicting the damage to the living plant mechanically mimicking the herbivore feeding, with a simple method not requiring insects [60, $66,73]$. Subsequent studies however showed that the volatile emission is also significantly affected by the biological interaction induced by the attack [15].

The literature reports several examples of investigations concerning the volatile emissions of living plants under insect attack $[12,30,47,48,51,71-73,77,86]$, despite the complexity of the interactions between two different living systems. In general, the larvae of the insect are placed in contact with a target part of the plant, mainly flowers $[48,51]$ or leaves $[30,48,71$, 86] where they feed, thus inducing the plant response. An innovative experimental set-up proposed by Crespo et al. [47] focused on the monitoring of belowground fly larvae feeding on Brassica nigra roots. The PTR-MS detector enabled to observe the progression of larvae 
feeding by monitoring the emission of sulfur compounds and other glucosinolate breakdown products from the roots.

Other BVOCs undergoing a considerable variation after herbivore attack are terpenoids $[30,51$, 71, 86], methanol [30], and green-leaf volatiles (GLVs) ( $\mathrm{C}_{6}$ alcohols, aldehydes, acetates...); these plant specialized metabolites form rapidly under abiotic/biotic stresses $[15,71]$.

DC-STE proved to be a valid sampling technique to monitor the volatiles related to herbivoreplant interactions $[12,15]$, and it has also exploited to investigate plant response to abiotic stress, such as mechanical damage [15] and hormone treatment [12]. In particular, Boggia et al. successfully used DC-STE characteristics to carry out a topographical evaluation of plant response to herbivore feeding and mechanical damage. The results demonstrated that the model plant (lima bean, Phaseolus lunatus) differently responded to cotton leafworm attack (Spodoptera littoralis) and mechanical stress, while the addition of insect oral secretions to mechanical damage stimulated an emission more similar to that of the leafworm attack. Moreover, the biomolecular analysis of the leaves showed that some HIVPs were influenced in their own gene expression in distant tissue while other volatiles are biosynthesized only near to the wounded area [15].

Caceres et al. have also investigated the relationship between volatile emissions and BVOC gene expression. In this case, an Arabidopsis thaliana L. Heynh. plant was genetically modified to overexpress the $C C D 1$ gene, which is related to the transformation of carotenoids into volatile apocarotenoids, which are important compounds for plant communication. The transgenic plant and the wild type presented similar volatile profiles except for $\beta$-ionone, an apocarotenoid which had a repellent effect against herbivores [50].

The response of living plants to insect stress varies according to a variety of stimuli. FarréArmengol et al. conducted a double experiment where a Diplotaxis erucoides (L.) DC. plant was subjected to flower and leaf herbivory (i.e. "folivory" and "florivory") by Pieris brassicae larvae. The results highlighted that folivory did not lead to a significative increase of the 
emission rates of floral BVOCs, while the association of folivory and florivory highly intensified the chemical defensive response. This may suggest that plants take advantage from widespread degree of infestation by increasing their defence compared to when the damages are limited and localized [48]. Different BVOC profiles were also reported when single and multiple pest infestations occur. Moreover, DC-SBSE with Twisters (see section 2.1.3) allowed to monitor the adaxial and abaxial leaf epidermis simultaneously, showing different emissions of specific classes of BVOC [86].

Most studies consider the insect-plant system as a whole and are unable to distinguish between the volatiles emitted by herbivores and plants. To overcome this limit, Fernandes et al. have monitored the interaction between Pieris brassicae and a kale plant with a different approach, i.e. by sampling the larvae fed with kale, both separately to the host plant and in conjunction. The analysis of the isolated larvae highlighted the presence of some compounds that were not detected in the kale volatilome, showing that the insects contribute to the volatile background [71]. Similarly, Vercammen et al. analysed individually the insect and its excrement to verify the specificity of the BVOCs that were detected in the headspace of the plants. The use of a specific D-HS set-up with two enclosures (see above), with the whole plants placed in a glass bulb, allowed to carry out differential stress experiments by D-HS and to obtain highly reliable results because of the presence of the reference plant in the analysis system. Besides insect feeding, the leaf of the plant was wounded with endoscopic pliers and deprived of light by covering the sampling bulb with aluminium foil [18]. Other studies have included different plant stressors, such as mechanical damage or/and hormone exposure, in addition to insect feeding $[72,77]$.

Cordero et al. applied HS-SPME combined with comprehensive two-dimensional GCquadrupole-MS (GC $\times \mathrm{GC}-\mathrm{qMS})$ with dedicated comparative data elaboration to discriminate chemical fingerprinting resulting from the interaction between some Mentha species and the herbivore Chrysolina herbacea, also known as the mint bug. C. herbacea was fed on different 
living Mentha species (M. spicata L., M. × piperita L. and M. longifolia L.), producing frass (faeces) with a diagnostic volatile fraction. The advanced fingerprinting analysis of the frass volatile fraction indicated the presence of: i) several hydroxy-1,8-cineoles derived from 1,8cineole, a component of the leaves of the investigated Mentha species, ii) several unknown oxidized monoterpenes, iii) a $p$-menthane diol, and iv) three unknown phenylpropanoids. The resistance of $M$. longifolia to the attack with insect death was associated to the presence of piperitenone oxide [98].

The in-vivo investigation of the volatile response of living plants to pathogens, which is considered to be a biotic stress, has been less thoroughly explored. These investigations are useful to develop rapid and sensitive techniques to monitor plant-health status in agricultural procedures without damaging the plant, especially for highly harmful infections. McCartny et al. demonstrated that healthy and infected Citrus spp. trees present different BVOC profiles after sampling with non-invasive dynamic sampling [39].

\section{Conclusions and future trends}

The in-vivo analysis of the volatiles emitted by a plant is a fundamental step to clarify its behaviour when it is submitted to a stress or a multitrophic interaction. The correct choice of the sampling approach in combination with a compatible analytical platform is essential to obtain meaningful information about the plant metabolome but it requires the development of dedicated analytical tools.

From the analytical point of view, the in-vivo collection of plant volatiles has required a great deal of effort to develop suitable sample-preparation systems, mainly based on either D-HS or S-HS sampling approaches. In this respect, devices that are based on direct contact sampling are a valid tool, not only to obtain appropriate analyte enrichment, but also to perform in-situ topographical studies. In addition to the choice of the sample-preparation technique, the adoption of the appropriate quantification method is a further crucial point to obtain reliable 
results. Meanwhile, it has to be remarked that only a few examples with in-situ-analysis have been reported, mainly with GC, even though in-field GC with portable instruments would provide analysis immediately after (or on-line to) in-field sampling, and markedly reduce experimental time. Micro-GCs, and, in particular, those based on microelectromechanicalsystem (MEMS) technology, are a valid future perspective for this field and worthy of further investigation [99].

The metabolomics related to the BVOC emission is extremely widespread and complex, and its exploration has just started. In particular, investigations are under way on the biosynthetic pathway of these metabolites, starting from the genes involved in their biosynthesis and their expression, to the factors inducing their formation. In this regard, a great deal of effort is currently directed to the investigation of plant-insect (or animal, in general) and plant-plant interactions. However, special attention should also be paid to plant-pathogen interactions not only to monitor the plant-health status, but also the changes in the plant volatilome that can alter their biological properties, in particular for those used in the food and health field.

\section{Acknowledgements}

The work was financially supported by the 'Ricerca Locale' (Ex60\%2019) project of the University of Turin, Turin (Italy). This article is based upon work from the Sample Preparation Task Force and Network supported by the Division of Analytical Chemistry of the European Chemical Society.

\section{References}

[1] D. Tholl, W. Boland, A. Hansel, F. Loreto, U.S. Rose, J.P. Schnitzler, Practical approaches to plant volatile analysis, Plant J 45(4) (2006) 540-60.

[2] M.E. Maffei, J. Gertsch, G. Appendino, Plant volatiles: Production, function and pharmacology, Nat Prod Rep 28(8) (2011) 1359-1380. 
[3] C. Bicchi, M. Maffei, The Plant Volatilome: Methods of Analysis, in: J. Normanly (Ed.), High-Throughput Phenotyping in Plants: Methods and Protocols, Humana Press, Totowa, NJ, 2012, pp. 289-310.

[4] S.G. Oliver, M.K. Winson, D.B. Kell, F. Baganz, Systematic functional analysis of the yeast genome, Trends Biotechnol 16(9) (1998) 373-8.

[5] S. Risticevic, E.A. Souza-Silva, E. Gionfriddo, J.R. DeEll, J. Cochran, W.S. Hopkins, J. Pawliszyn, Application of in vivo solid phase microextraction (SPME) in capturing metabolome of apple (Malus domestica Borkh.) fruit, Sci Rep 10(1) (2020) 6724.

[6] J.A. Ocaña-González, R. Fernández-Torres, M.Á. Bello-López, M. Ramos-Payán, New developments in microextraction techniques in bioanalysis. A review, Anal Chim Acta 905 (2016) 8-23.

[7] S. Risticevic, E.A. Souza-Silva, J.R. DeEll, J. Cochran, J. Pawliszyn, Capturing Plant Metabolome with Direct-Immersion in Vivo Solid Phase Microextraction of Plant Tissues, Anal Chem 88(2) (2016) 1266-74.

[8] M. mossaddegh, H. Kazerooni, In Vivo Solid-Phase Microextraction: An Efficient Sample Preparation Method for Plant and Tissue Bioanalysis, Biquarterly Iranian Journal of Analytical Chemistry 6(2) (2019) 39-53.

[9] T. Majchrzak, W. Wojnowski, M. Rutkowska, A. Wasik, Real-Time Volatilomics: A Novel Approach for Analyzing Biological Samples, Trends Plant Sci 25(3) (2020) 302-312.

[10] F. Zhu, J. Xu, Y. Ke, S. Huang, F. Zeng, T. Luan, G. Ouyang, Applications of in vivo and in vitro solid-phase microextraction techniques in plant analysis: A review, Anal Chim Acta 794 (2013) 1-14.

[11] A. Manzo, S. Panseri, I. Vagge, A. Giorgi, Volatile fingerprint of italian populations of orchids using solid phase microextraction and gas chromatography coupled with mass spectrometry, Molecules 19(6) (2014) 7913-36. 
[12] N. Kfoury, E. Scott, C. Orians, A. Robbat, Jr., Direct Contact Sorptive Extraction: A Robust Method for Sampling Plant Volatiles in the Field, J Agric Food Chem 65(38) (2017) 8501-8509.

[13] X. Deng, J. Peng, B. Luo, M. Wei, W. Hu, J. Du, A direct quantitative analysis method for monitoring biogenic volatile organic compounds released from leaves of Pelargonium hortorum in situ, Anal Bioanal Chem 380(7-8) (2004) 950-7.

[14] B. Sgorbini, C. Cagliero, C. Cordero, E. Liberto, P. Rubiolo, C. Bicchi, Headspace Sampling and Gas Chromatography of Plants: a Successful Combination to Study the Composition of a Plant Volatile Fraction, in: K. Hostettmann, H. Stuppner, A. Marston, S. Chen (Eds.), Encyclopedia of Analytical Chemistry, John Wiley \& Sons, Ltd2014, pp. 1-10.

[15] L. Boggia, B. Sgorbini, C.M. Bertea, C. Cagliero, C. Bicchi, M.E. Maffei, P. Rubiolo, Direct Contact - Sorptive Tape Extraction coupled with Gas Chromatography - Mass Spectrometry to reveal volatile topographical dynamics of lima bean (Phaseolus lunatus L.) upon herbivory by Spodoptera littoralis Boisd, BMC Plant Biol 15 (2015) 102.

[16] O. Wahlroos, O.E. Nikkilä, Quantitative determination of volatile compounds from food and evaluation of the gas flushing method for their concentration, Acta Chem Scand 20(1) (1966) 197-205.

[17] V. Herout, [Gas chromatography of terpendoids], Planta Med (1967) 68-78.

[18] J. Vercammen, H. Pham-Tuan, P. Sandra, Automated dynamic sampling system for the on-line monitoring of biogenic emissions from living organisms, J Chromatogr A 930(1-2) (2001) 39-51.

[19] J. Beauchamp, A. Wisthaler, A. Hansel, E. Kleist, M. Miebach, Ü. Niinemets, U.L.I. Schurr, J. Wildt, Ozone induced emissions of biogenic VOC from tobacco: relationships between ozone uptake and emission of LOX products, Plant Cell Environ 28(10) (2005) 13341343. 
[20] U. Effmert, J. Große, U.S. Röse, F. Ehrig, R. Kägi, B. Piechulla, Volatile composition, emission pattern, and localization of floral scent emission in Mirabilis jalapa (Nyctaginaceae), Am J Bot 92(1) (2005) 2-12.

[21] B. Baker, M. Sinnott, Analysis of sesquiterpene emissions by plants using solid phase microextraction, J Chromatogr A 1216(48) (2009) 8442-51.

[22] M. Staudt, L. Lhoutellier, Monoterpene and sesquiterpene emissions from Quercus coccifera exhibit interacting responses to light and temperature, Biogeosciences 8(9) (2011) $2757-2771$.

[23] L.M. Feijo Barreira, G. Duporte, J. Parshintsev, K. Hartonen, M. Jussila, J. Aalto, J. Bäck, M. Kulmala, M.-L. Riekkola, Emissions of biogenic volatile organic compounds from the boreal forest floor and understory: a study by solid-phase microextraction and portable gas chromatography-mass spectrometry, Boreal Environ Res 22 (2017) 393-413.

[24] C. Geron, A. Guenther, T. Sharkey, R.R. Arnts, Temporal variability in basal isoprene emission factor, Tree Physiol 20(12) (2000) 799-805.

[25] R. Holzinger, L. Sandoval-Soto, S. Rottenberger, P.J. Crutzen, J. Kesselmeier, Emissions of volatile organic compounds from Quercus ilex L. measured by Proton Transfer Reaction Mass Spectrometry under different environmental conditions, J Geophys Res-Atmos 105(D16) (2000) 20573-20579.

[26] G. Pétron, P. Harley, J. Greenberg, A. Guenther, Seasonal temperature variations influence isoprene emission, Geophys Res Lett 28(9) (2001) 1707-1710.

[27] S.M. Owen, P. Harley, A. Guenther, C.N. Hewitt, Light dependency of VOC emissions from selected Mediterranean plant species, Atmos Environ 36(19) (2002) 3147-3159.

[28] E.I. Boamfa, M.M.L. Steeghs, S.M. Cristescu, F.J.M. Harren, Trace gas detection from fermentation processes in apples; an intercomparison study between proton-transfer-reaction mass spectrometry and laser photoacoustics, Int J Mass Spectrom 239(2-3) (2004) 193-201. 
[29] M. Graus, J.P. Schnitzler, A. Hansel, C. Cojocariu, H. Rennenberg, A. Wisthaler, J. Kreuzwieser, Transient release of oxygenated volatile organic compounds during light-dark transitions in Grey poplar leaves, Plant Physiol 135(4) (2004) 1967-75.

[30] J. Penuelas, I. Filella, C. Stefanescu, J. Llusia, Caterpillars of Euphydryas aurinia (Lepidoptera: Nymphalidae) feeding on Succisa pratensis leaves induce large foliar emissions of methanol, New Phytol 167(3) (2005) 851-7.

[31] T. Dindorf, U. Kuhn, L. Ganzeveld, G. Schebeske, P. Ciccioli, C. Holzke, R. Köble, G. Seufert, J. Kesselmeier, Significant light and temperature dependent monoterpene emissions from European beech (Fagus sylvaticaL.) and their potential impact on the European volatile organic compound budget, J Geophys Res 111(D16) (2006).

[32] S. Moukhtar, C. Couret, L. Rouil, V. Simon, Biogenic volatile organic compounds (BVOCs) emissions from Abies alba in a French forest, Sci Total Environ 354(2-3) (2006) 23245.

[33] J. Kreuzwieser, U. Scheerer, J. Kruse, T. Burzlaff, A. Honsel, S. Alfarraj, P. Georgiev, J.P. Schnitzler, A. Ghirardo, I. Kreuzer, R. Hedrich, H. Rennenberg, The Venus flytrap attracts insects by the release of volatile organic compounds, J Exp Bot 65(2) (2014) 755-66.

[34] T.G. Malik, T. Gajbhiye, S.K. Pandey, Plant specific emission pattern of biogenic volatile organic compounds (BVOCs) from common plant species of Central India, Environ Monit Assess 190(11) (2018) 631.

[35] D. Helmig, J. Ortega, A. Guenther, J.D. Herrick, C. Geron, Sesquiterpene emissions from loblolly pine and their potential contribution to biogenic aerosol formation in the Southeastern US, Atmos Environ 40(22) (2006) 4150-4157.

[36] D. Helmig, J. Ortega, T. Duhl, D. Tanner, A. Guenther, P. Harley, C. Wiedinmyer, J. Milford, T. Sakulyanontvittaya, Sesquiterpene Emissions from Pine Trees - Identifications, 
Emission Rates and Flux Estimates for the Contiguous United States, Environ Sci Technol $41(5)(2007)$ 1545-1553.

[37] N.C. Bouvier-Brown, R. Holzinger, K. Palitzsch, A.H. Goldstein, Large emissions of sesquiterpenes and methyl chavicol quantified from branch enclosure measurements, Atmos Environ 43(2) (2009) 389-401.

[38] S.N. Matsunaga, S. Chatani, S. Nakatsuka, D. Kusumoto, K. Kubota, Y. Utsumi, T. Enoki, A. Tani, T. Hiura, Determination and potential importance of diterpene (kaur-16-ene) emitted from dominant coniferous trees in Japan, Chemosphere 87(8) (2012) 886-93.

[39] M.M. McCartney, S.L. Spitulski, A. Pasamontes, D.J. Peirano, M.J. Schirle, R. Cumeras, J.D. Simmons, J.L. Ware, J.F. Brown, A.J. Poh, S.C. Dike, E.K. Foster, K.E. Godfrey, C.E. Davis, Coupling a branch enclosure with differential mobility spectrometry to isolate and measure plant volatiles in contained greenhouse settings, Talanta 146 (2016) 148-54.

[40] F. Chen, D. Tholl, J.C. D'Auria, A. Farooq, E. Pichersky, J. Gershenzon, Biosynthesis and emission of terpenoid volatiles from Arabidopsis flowers, Plant Cell 15(2) (2003) 481-94.

[41] S. Pressley, Monoterpene emissions from a Pacific Northwest Old-Growth Forest and impact on regional biogenic VOC emission estimates, Atmos Environ 38(19) (2004) 30893098.

[42] C.-Y. Lin, T.-C. Chang, Y.-H. Chen, Y.-J. Chen, S.-S. Cheng, S.-T. Chang, Monitoring the dynamic emission of biogenic volatile organic compounds from Cryptomeria japonica by enclosure measurement, Atmos Environ 122 (2015) 163-170.

[43] I. Vedel-Petersen, M. Schollert, J. Nymand, R. Rinnan, Volatile organic compound emission profiles of four common arctic plants, Atmos Environ 120 (2015) 117-126.

[44] R. Silva, N. Tinoco, A. Tsukui, C. Koschnitzke, I. Silva-Batista, C. Rezende, H. Bizzo, Floral Scent and Nectar Sugar Composition of Temnadenia odorifera (Apocynoideae, Apocynaceae), J Braz Chem Soc (2018). 
[45] E. Baltussen, F. David, P. Sandra, H.-G. Janssen, C. Cramers, Equilibrium Sorptive Enrichment on Poly(dimethylsiloxane) Particles for Trace Analysis of Volatile Compounds in Gaseous Samples, Anal Chem 71(22) (1999) 5193-5198.

[46] C. Holzke, T. Dindorf, J. Kesselmeier, U. Kuhn, R. Koppmann, Terpene emissions from European beech (shape Fagus sylvatica L.): Pattern and Emission Behaviour Over two Vegetation Periods, J Atmos Chem 55(1) (2006) 81-102.

[47] E. Crespo, C.A. Hordijk, R.M. de Graaf, D. Samudrala, S.M. Cristescu, F.J. Harren, N.M. van Dam, On-line detection of root-induced volatiles in Brassica nigra plants infested with Delia radicum L. root fly larvae, Phytochemistry 84 (2012) 68-77.

[48] G. Farré-Armengol, I. Filella, J. Llusia, C. Primante, J. Peñuelas, Enhanced emissions of floral volatiles by Diplotaxis erucoides (L.) in response to folivory and florivory by Pieris brassicae (L.), Biochem Syst Ecol 63 (2015) 51-58.

[49] C. Barrios-Collado, D. Garcia-Gomez, R. Zenobi, G. Vidal-de-Miguel, A.J. Ibanez, P. Martinez-Lozano Sinues, Capturing in Vivo Plant Metabolism by Real-Time Analysis of Low to High Molecular Weight Volatiles, Anal Chem 88(4) (2016) 2406-12.

[50] L.A. Caceres, S. Lakshminarayan, K.K. Yeung, B.D. McGarvey, A. Hannoufa, M.W. Sumarah, X. Benitez, I.M. Scott, Repellent and Attractive Effects of alpha-, beta-, and Dihydrobeta- Ionone to Generalist and Specialist Herbivores, J Chem Ecol 42(2) (2016) 107-17.

[51] U.S. Rose, J.H. Tumlinson, Volatiles released from cotton plants in response to Helicoverpa zea feeding damage on cotton flower buds, Planta 218(5) (2004) 824-32.

[52] N. Yassaa, B. Youcef Meklati, A. Cecinato, Evaluation of monoterpenic biogenic volatile organic compounds in ambient air around Eucalyptus globulus, Pinus halepensis and Cedrus atlantica trees growing in Algiers city area by chiral and achiral capillary gas chromatography, Atmos Environ 34(17) (2000) 2809-2816.

[53] V. Tarvainen, H. Hakola, H. Hellén, J. Bäck, P. Hari, M. Kulmala, Temperature and light dependence of the VOC emissions of Scots pine, Atmos. Chem. Phys. 5(4) (2005) 989-998. 
[54] N.C. Bouvier-Brown, R. Holzinger, K. Palitzsch, A.H. Goldstein, Quantifying sesquiterpene and oxygenated terpene emissions from live vegetation using solid-phase microextraction fibers, J Chromatogr A 1161(1-2) (2007) 113-20.

[55] N. Yassaa, J. Williams, Enantiomeric monoterpene emissions from natural and damaged Scots pine in a boreal coniferous forest measured using solid-phase microextraction and gas chromatography/mass spectrometry, J Chromatogr A 1141(1) (2007) 138-44.

[56] J.F. Pankow, W. Luo, A.N. Melnychenko, K.C. Barsanti, L.M. Isabelle, C. Chen, A.B. Guenther, T.N. Rosenstiel, Volatilizable Biogenic Organic Compounds (VBOCs) with two dimensional Gas Chromatography-Time of Flight Mass Spectrometry (GC \&times; GCTOFMS): sampling methods, VBOC complexity, and chromatographic retention data, Atmos Meas Tech 5(2) (2012) 345-361.

[57] S. Huang, G. Chen, N. Ye, X. Kou, F. Zhu, J. Shen, G. Ouyang, Solid-phase microextraction: An appealing alternative for the determination of endogenous substances - A review, Anal Chim Acta 1077 (2019) 67-86.

[58] Z.Y. Zhang, J. Pawliszyn, Headspace Solid-Phase Microextraction. Anal Chem 65(14) (1993) 1843-1852.

[59] É.A. Souza-Silva, J. Pawliszyn, Chapter Sixteen - Recent Advances in Solid-Phase Microextraction for Contaminant Analysis in Food Matrices, in: E. Ibáñez, A. Cifuentes (Eds.), Comprehensive Analytical Chemistry, Elsevier2017, pp. 483-517.

[60] D.A. Vereen, J.P. McCall, D. J. Butcher, Solid phase microextraction for the determination of volatile organics in the foliage of Fraser fir (Abies fraseri), Microchem J 65(3) (2000) 269276.

[61] G. Flamini, P.L. Cioni, I. Morelli, Analysis of the essential oil of the aerial parts of Viola etrusca from Monte Labbro (South Tuscany, Italy) and in vivo analysis of flower volatiles using SPME, Flavour Fragr J 17(2) (2002) 147-149. 
[62] J.C. Verdonk, C.H. Ric de Vos, H.A. Verhoeven, M.A. Haring, A.J. van Tunen, R.C. Schuurink, Regulation of floral scent production in petunia revealed by targeted metabolomics, Phytochemistry 62(6) (2003) 997-1008.

[63] G. Flamini, P.L. Cioni, I. Morelli, S. Maccioni, R. Baldini, Phytochemical typologies in some populations of Myrtus communis L. on Caprione Promontory (East Liguria, Italy), Food Chem 85(4) (2004) 599-604.

[64] G. Flamini, P.L. Cioni, I. Morelli, Composition of the essential oils and in vivo emission of volatiles of four Lamium species from Italy: L. purpureum, L. hybridum, L. bifidum and L. amplexicaule, Food Chem 91(1) (2005) 63-68.

[65] S. Maccioni, R. Baldini, P.L. Cioni, M. Tebano, G. Flamini, In vivo volatiles emission and essential oils from different organs and pollen of Cistus albidus from Caprione (Eastern Liguria, Italy), Flavour Fragr J 22(1) (2007) 61-65.

[66] J.J. Beck, L. Smith, G.B. Merrill, In situ volatile collection, analysis, and comparison of three Centaurea species and their relationship to biocontrol with herbivorous insects, J Agric Food Chem 56(8) (2008) 2759-64.

[67] G. Flamini, P.L. Cioni, Odour gradients and patterns in volatile emission of different plant parts and developing fruits of grapefruit (Citrus paradisi L.), Food Chem 120(4) (2010) 984992.

[68] J. Meija, M. Montes-Bayón, D.L. Le Duc, N. Terry, J.A. Caruso, Simultaneous monitoring of volatile selenium and sulfur species from se accumulating plants (wild type and genetically modified) by GC/MS and GC/ICPMS using solid-phase microextraction for sample introduction, Anal Chem 74(22) (2002) 5837-44.

[69] G. Song, J. Xiao, C. Deng, X. Zhang, Y. Hu, Use of solid-phase microextraction as a sampling technique for the characterization of volatile compounds emitted from Chinese daffodil flowers, Journal of Anal Chem 62(7) (2007) 674-679. 
[70] G. Moreno-Martin, J. Sanz-Landaluze, M.E. Leon-Gonzalez, Y. Madrid, In-vivo solid phase microextraction for quantitative analysis of volatile organoselenium compounds in plants, Anal Chim Acta 1081 (2019) 72-80.

[71] F. Fernandes, D.M. Pereira, P. Guedes de Pinho, P. Valentão, J.A. Pereira, A. Bento, P.B. Andrade, Headspace solid-phase microextraction and gas chromatography/ion trap-mass spectrometry applied to a living system: Pieris brassicae fed with kale, Food Chem 119(4) (2010) 1681-1693.

[72] M. Danielsson, T. Zhao, A.-K. Borg-Karlson, Arthropod infestation sites and induced defence can be traced by emission from single spruce needles, Arthropod-Plant Inte 13(2) (2019) 253-259.

[73] C.A. Zini, F. Augusto, E. Christensen, B.P. Smith, E.B. Caramão, J. Pawliszyn, Monitoring Biogenic Volatile Compounds Emitted by Eucalyptus citriodora Using SPME, Anal Chem 73(19) (2001) 4729-4735.

[74] E.E. Stashenko, S. Andrés Ordóñez, N.A. Marín, J.R. Martínez, Determination of the volatile and semi-volatile secondary metabolites, and aristolochic acids in Aristolochia ringens Vahl, J Chromatogr Sci 47(9) (2009) 817-21.

[75] A. Bar-Akiva, R. Ovadia, I. Rogachev, C. Bar-Or, E. Bar, Z. Freiman, A. Nissim-Levi, N. Gollop, E. Lewinsohn, A. Aharoni, D. Weiss, H. Koltai, M. Oren-Shamir, Metabolic networking in Brunfelsia calycina petals after flower opening, J Exp Bot 61(5) (2010) 1393403.

[76] Y.-J. Chen, S.-S. Cheng, S.-T. Chang, Monitoring the emission of volatile organic compounds from the leaves of Calocedrus macrolepis var. formosana using solid-phase microextraction, J Wood Sci 56(2) (2010) 140-147.

[77] A. Giorgi, A. Manzo, N.N. Nanayakkara, L. Giupponi, M. Cocucci, S. Panseri, Effect of biotic and abiotic stresses on volatile emission of Achillea collina Becker ex Rchb, Nat Prod Res 29(18) (2015) 1695-702. 
[78] E.J. Eilers, G. Pauls, M.C. Rillig, B.S. Hansson, M. Hilker, A. Reinecke, Novel Set-Up for Low-Disturbance Sampling of Volatile and Non-volatile Compounds from Plant Roots, J Chem Ecol 41(3) (2015) 253-66.

[79] L. Zhang, E. Gionfriddo, V. Acquaro, Jr., J. Pawliszyn, Direct immersion solid-phase microextraction analysis of multi-class contaminants in edible seaweeds by gas chromatography-mass spectrometry, Anal Chim Acta 1031 (2018) 83-97.

[80] E. Gionfriddo, É.A. Souza-Silva, J. Pawliszyn, Headspace versus Direct Immersion Solid Phase Microextraction in Complex Matrixes: Investigation of Analyte Behavior in Multicomponent Mixtures, Anal Chem 87(16) (2015) 8448-8456.

[81] N. Reiche, F. Mothes, P. Fiedler, H. Borsdorf, A solid-phase microextraction method for the in vivo sampling of MTBE in common reed (Phragmites australis), Environ Monit Assess 185(9) (2013) 7133-44.

[82] R.X. Loi, M.C. Solar, J.D. Weidenhamer, Solid-phase microextraction method for in vivo measurement of allelochemical uptake, J Chem Ecol 34(1) (2008) 70-5.

[83] G. Chen, J. Qiu, Y. Liu, R. Jiang, S. Cai, Y. Liu, F. Zhu, F. Zeng, T. Luan, G. Ouyang, Carbon Nanotubes Act as Contaminant Carriers and Translocate within Plants, Sci Rep 5 (2015) 15682.

[84] S. Sisalli, A. Adao, M. Lebel, I. Fur, P. Sandra, Sorptive Tape Extraction - A Novel Sampling Method for the In Vivo Study of Skin, LC GC Europe 19 (2006) 33-39.

[85] C. Bicchi, C. Cordero, E. Liberto, P. Rubiolo, B. Sgorbini, P. Sandra, Sorptive tape extraction in the analysis of the volatile fraction emitted from biological solid matrices, Journal of Chromatography A 1148(2) (2007) 137-144.

[86] A. Errard, C. Ulrichs, S. Kuhne, I. Mewis, M. Drungowski, M. Schreiner, S. Baldermann, Single- versus Multiple-Pest Infestation Affects Differently the Biochemistry of Tomato (Solanum lycopersicum 'Ailsa Craig'), J Agric Food Chem 63(46) (2015) 10103-11. 
[87] B. Sgorbini, C. Cagliero, E. Liberto, P. Rubiolo, C. Bicchi, C. Cordero, Strategies for Accurate Quantitation of Volatiles from Foods and Plant-Origin Materials: A Challenging Task, J Agr Food Chem 67(6) (2019) 1619-1630.

[88] P. Schieberle, W. Grosch, Quantitative analysis of aroma compounds in wheat and rye bread crusts using a stable isotope dilution assay, J Agr Food Chem 35(2) (1987) 252-257.

[89] Y. Wang, J. O’Reilly, Y. Chen, J. Pawliszyn, Equilibrium in-fibre standardisation technique for solid-phase microextraction, J Chromatogr A 1072(1) (2005) 13-17.

[90] R.A. Miller, G.A. Eiceman, E.G. Nazarov, A.T. King, A novel micromachined high-field asymmetric waveform-ion mobility spectrometer, Sensors Actuat B Chem 67(3) (2000) 300306.

[91] N.M. van Dam, G.M. Poppy, Why plant volatile analysis needs bioinformatics--detecting signal from noise in increasingly complex profiles, Plant Biol (Stuttg) 10(1) (2008) 29-37.

[92] M. D'Alessandro, T.C. Turlings, Advances and challenges in the identification of volatiles that mediate interactions among plants and arthropods, Analyst 131(1) (2006) 24-32.

[93] J. Ortega, D. Helmig, Approaches for quantifying reactive and low-volatility biogenic organic compound emissions by vegetation enclosure techniques - Part A, Chemosphere 72(3) (2008) 343-364.

[94] J. Ortega, D. Helmig, R.W. Daly, D.M. Tanner, A.B. Guenther, J.D. Herrick, Approaches for quantifying reactive and low-volatility biogenic organic compound emissions by vegetation enclosure techniques - Part B: Applications, Chemosphere 72(3) (2008) 365-380.

[95] M. Staudt, I. Bourgeois, R. Al Halabi, W. Song, J. Williams, New insights into the parametrization of temperature and light responses of mono - and sesquiterpene emissions from Aleppo pine and rosemary, Atmos Environ 152 (2017) 212-221.

[96] A.B. Guenther, P.R. Zimmerman, P.C. Harley, R.K. Monson, R. Fall, Isoprene and monoterpene emission rate variability: Model evaluations and sensitivity analyses, J Geophys Res Atmos 98(D7) (1993) 12609-12617. 
[97] G. Petron, P. Harley, J. Greenberg, A. Guenther, Seasonal temperature influence isoprene emission, Geophys Res Lett 28 (2001) 1707-1710.

[98] C. Cordero, S.A. Zebelo, G. Gnavi, A. Griglione, C. Bicchi, M.E. Maffei, P. Rubiolo, HSSPME-GC $\times$ GC-qMS volatile metabolite profiling of Chrysolina herbacea frass and Mentha spp. leaves, Anal Bioanal Chem 402(5) (2012) 1941-52.

[99] C. Cagliero, S. Galli, M. Galli, I. Elmi, M. Belluce, S. Zampolli, B. Sgorbini, P. Rubiolo, C. Bicchi, Conventional and enantioselective GC with microfabricated planar columns for analysis of real-world samples of plant volatile fraction, J Chromatogr A 1429 (2016) 329-339. 

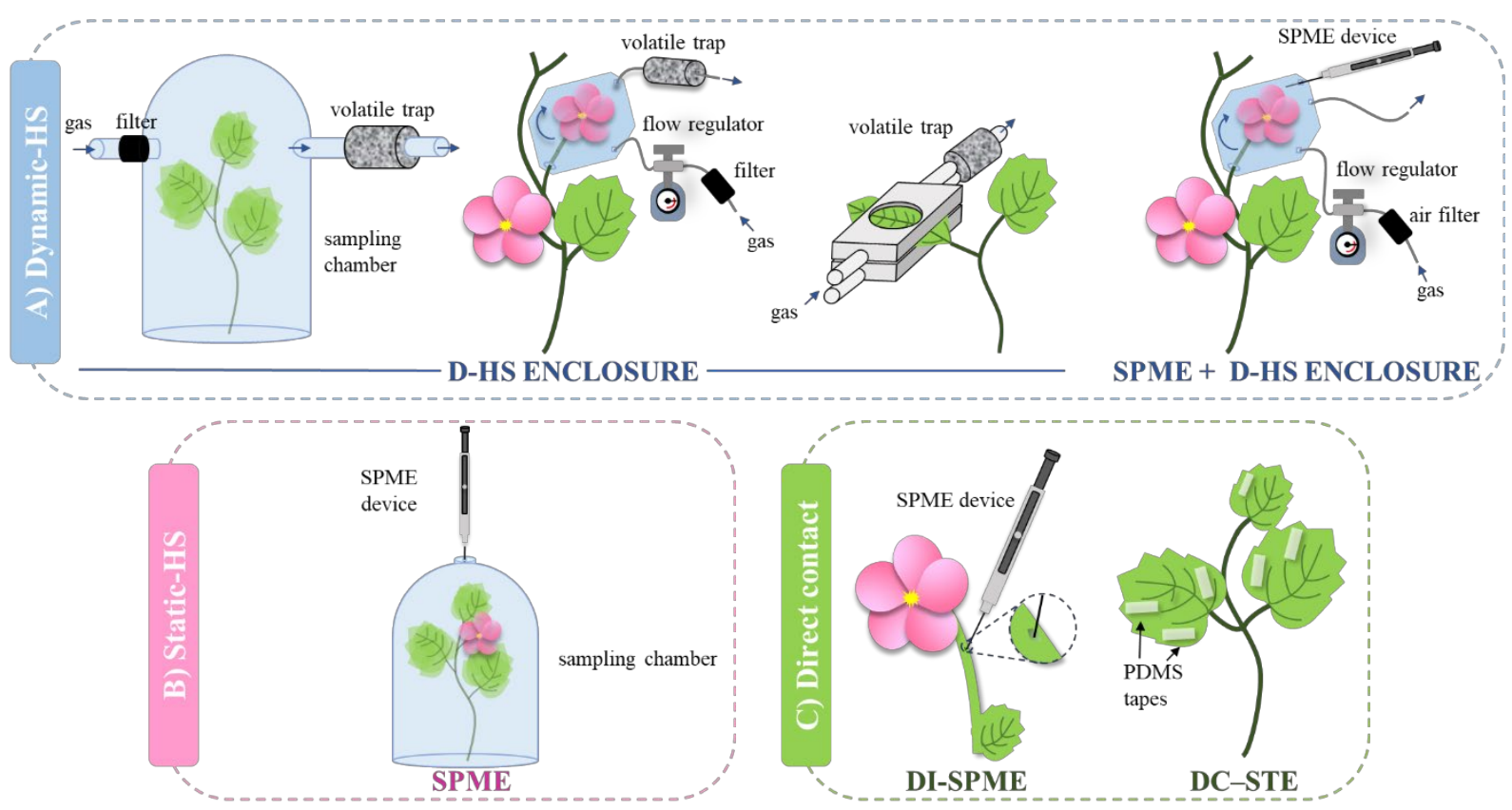

Figure 1. Most representative examples of in-vivo BVOC sampling techniques from living plants: A) Dynamic-headspace (D-HS), B) Satic-HS (S-HS) and C) Direct contact (DC) sampling. Black and white figure for the printed version. 

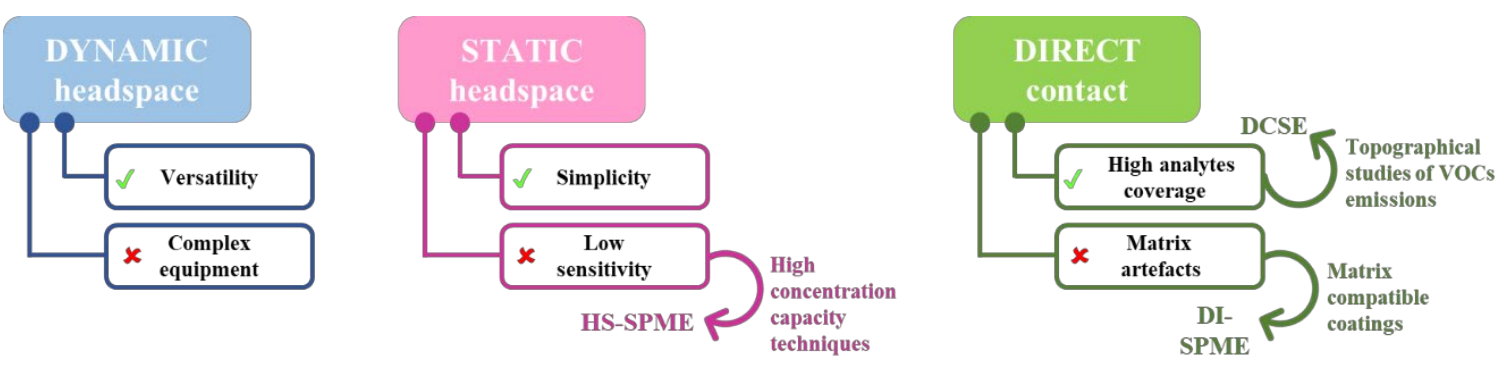

Figure 2. Advantages and disadvantages of the main sampling techniques employed for the invivo characterisation of BVOCs in living plants. Black and white figure for the printed version. 

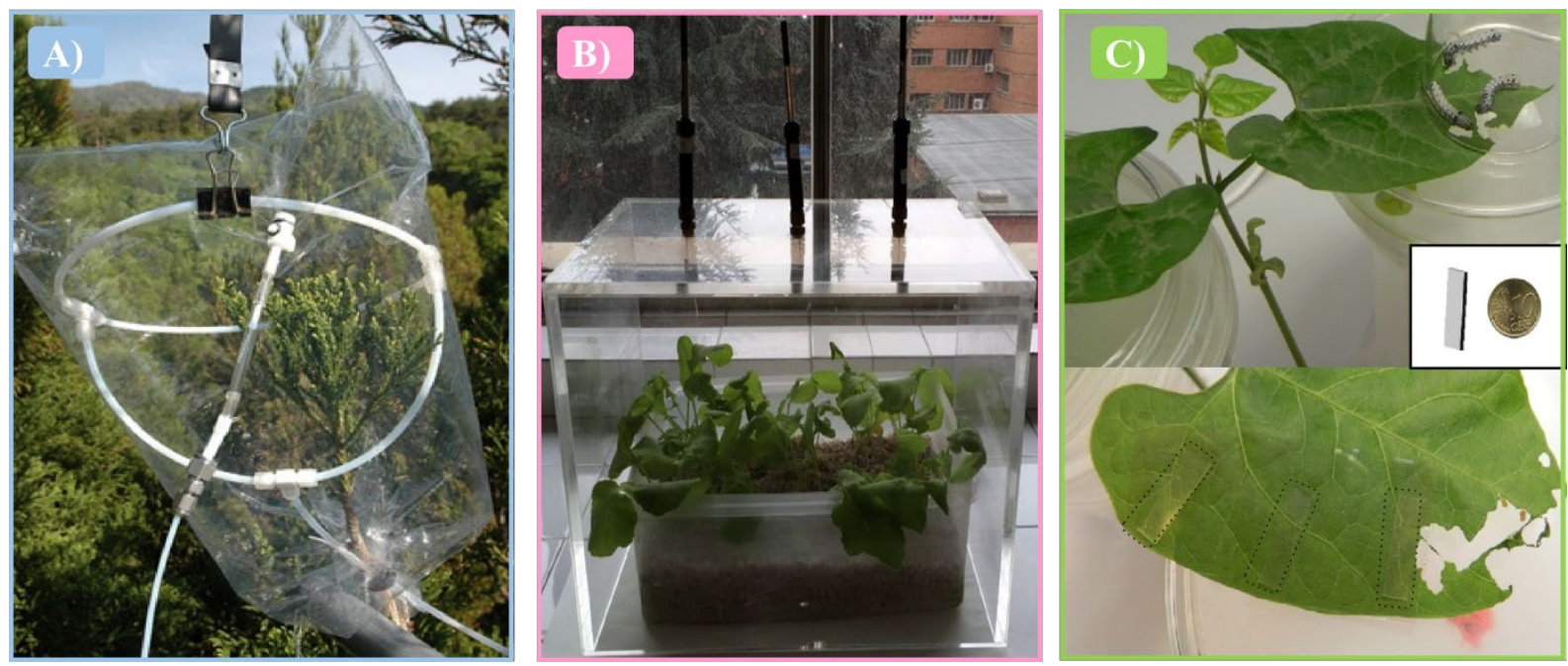

Figure 3. Examples of BVOC sampling from living plants: A) Teflon bag dynamic enclosure, adapted from Ref. [38] with permission from Elsevier; B) Static HS-SPME, adapted from Ref. [70], with permission from Elsevier; C) DC-SE with PDMS tape, adapted from Ref. [15] with permission from Springer Nature. Black and white figure for the printed version. 


\section{A) Quantitation methods}

$\square$ Semi-Quantification

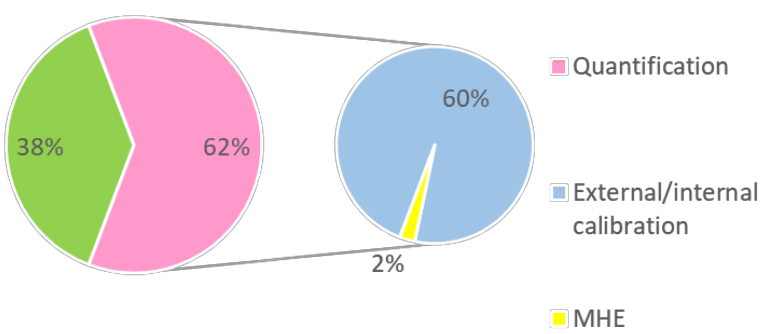

B) Analytical platforms

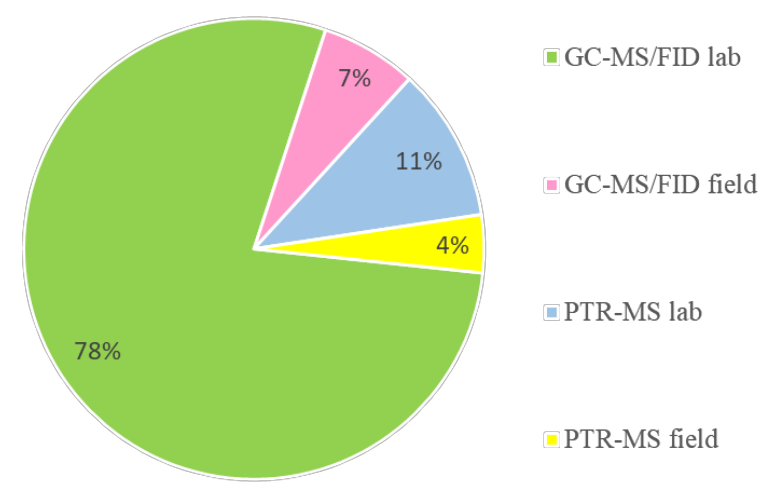

Figure 4. Percentage share of A) Methods for BVOCs quantification and B) Analytical platforms employed for in-vivo evaluation of plant emission. Black and white figure for the printed version. 

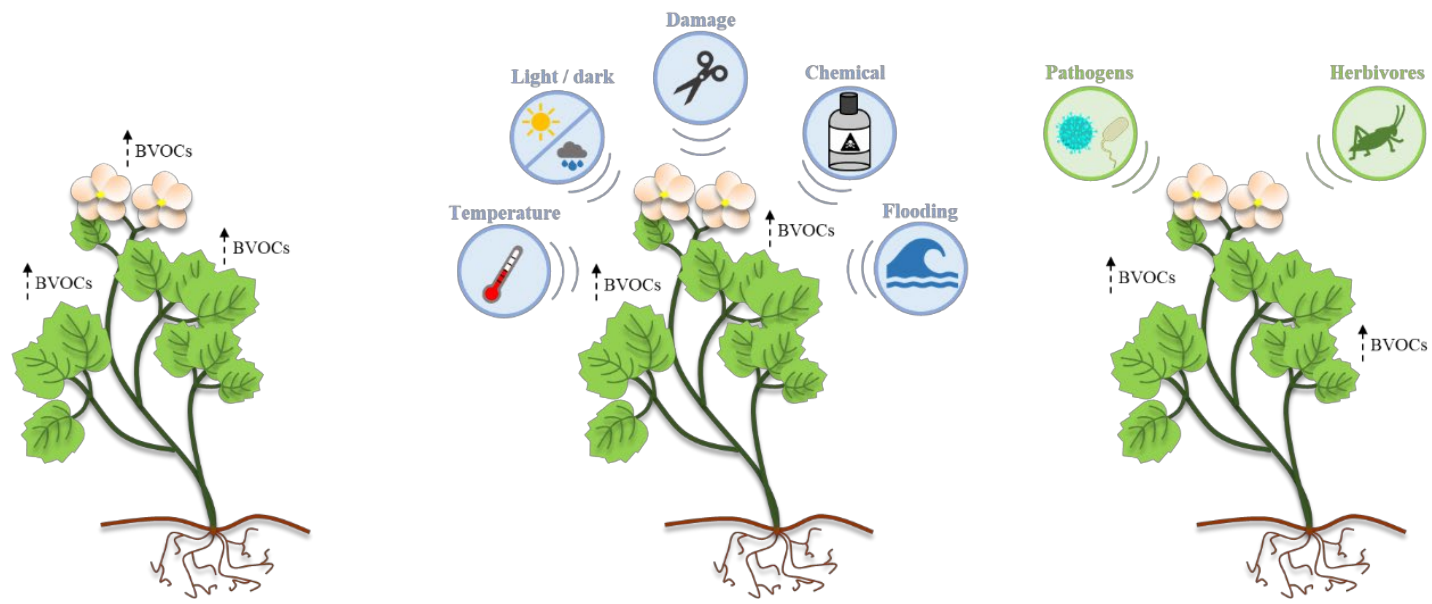

Figure 5. Main applications of volatilomic studies in living plants. Black and white figure for the printed version. 
Table 1. In-vivo studies on spontaneous emissions by living plants: plant(s) and analytes investigated and sampling techniques, sorbent devices and analytical techniques applied

\begin{tabular}{|c|c|c|c|c|c|}
\hline Plant(s) & Analytes & Sampling technique & Sorbent device & $\begin{array}{l}\text { Analytical } \\
\text { technique }\end{array}$ & Ref. \\
\hline $\begin{array}{l}49 \text { plants spp. from Central } \\
\text { India }\end{array}$ & Monoterpenes, isoprene & D-HS enclosure & $\begin{array}{l}\text { 100/200 mg } \\
\text { TA/Carbosieve II }\end{array}$ & GC-FID & [34] \\
\hline Abies alba Mill. & Monoterpenes, isoprene & D-HS enclosure & $\begin{array}{l}60 / 80 \text { mg Tenax TA } \\
\text { mesh }\end{array}$ & GC-FID/MS & [32] \\
\hline $\begin{array}{l}\text { Arabidopsis thaliana (L.) } \\
\text { Heynh. }\end{array}$ & Terpenes & D-HS enclosure & $1.5 \mathrm{mg}$ charcoal & GC-MS & [40] \\
\hline Aristolochia ringens Vahl & $\begin{array}{l}\text { Terpenes, aldehydes, } \\
\text { carboxylic acids }\end{array}$ & SPME & $65 \mu \mathrm{m}, \mathrm{PDMS} / \mathrm{DVB}$ & GC-MS & [74] \\
\hline Brunfelsia calycina Benth. & $\begin{array}{l}\text { Terpenes, } \\
\text { phenylpropanoids }\end{array}$ & SPME & $65 \mu \mathrm{m}, \mathrm{PDMS} / \mathrm{DVB}$ & GC-MS & [75] \\
\hline $\begin{array}{l}\text { Cedrus atlantica (Endl.) } \\
\text { Manetti ex Carrière, } \\
\text { Calycolpus moritzianus } \\
\text { (O.Berg) Burret }\end{array}$ & Terpenes & $\begin{array}{l}\text { D-HS enclosure } \\
\text { coupled with SPME }\end{array}$ & $\begin{array}{l}\text { Tenax } \\
\text { TA/Carbotrap, } \\
\text { Tenax } \\
\text { GR/Carbograph }\end{array}$ & $\mathrm{GC} \times \mathrm{GC}-\mathrm{MS}$ & [56] \\
\hline Cistus albidus L. & $\begin{array}{l}\text { Sesquiterpenes, } \\
\text { monoterpenes }\end{array}$ & SPME & $100 \mu \mathrm{m}$ PDMS & GC-MS & [65] \\
\hline Citrus paradisi Macfad. & Terpenes & SPME & NA & GC-MS & [67] \\
\hline
\end{tabular}


Cryptomeria japonica (Thunb. Terpenes

ex L.f.) D.Don,

Chamaecyparis obtusa

(Siebold \& Zucc.) Endl.

Eucalyptus globulus Labill., Pinus halepensis Mill., Cedrus atlantica (Endl.) Manetti ex

\section{Carrière}

\section{Lamium spp.}

Malus domestica Borkh.

Mirabilis jalapa $\mathrm{L}$.

Myrtus communis L.

Narcissus tazetta L.

Ophyris spp., Neotinea tridentata (Scop.)

R.M.Bateman, Pridgeon \&

M.W.Chase

Pelargonium hortorum L.H. Bailey aldehydes

\section{Esters,}

hexanal esters
D-HS enclosure

60 mg HayeSep Q

GC-MS

[38]

Monoterpenes

D-HS enclosure

$100 / 50 \mathrm{mg}$ of $20 / 40$ mesh charcoal

GC-FID/MS

coconut shells

$100 \mu \mathrm{m}$ PDMS $\quad$ GC-MS

phenylpropanoids,

DI-SPME

$50 / 30 \mu \mathrm{m}$

$\mathrm{GC} \times \mathrm{GC}-\mathrm{MS}$

$\mathrm{PDMS} / \mathrm{DVB} / \mathrm{CAR}$

Terpenes, benzenoids

D-HS enclosure

Terpenes, aldehydes,

SPME

Terpenes, aldehydes,
esters, alcohols, phenols

SPME

Terpenes, benzenoids fatty acid derivatives
SPME

$75 \mu \mathrm{M}, \mathrm{PDMS} / \mathrm{CAR} \quad$ GC-MS
100 mg Super-Q

GC-MS

$100 \mu \mathrm{m}$ PDMS

GC-MS

$85 \mu \mathrm{m}, \mathrm{PDMS} / \mathrm{CAR} \quad$ GC-MS

GC-MS

50/30 $\mu \mathrm{m}$

$\mathrm{PDMS} / \mathrm{DVB} / \mathrm{CAR}$ 


\begin{tabular}{|c|c|c|c|c|c|}
\hline Petunia hybrida Vilm. & $\begin{array}{l}\text { Benzenoids, aldehydes, } \\
\text { terpenes, fatty acid } \\
\text { derivatives }\end{array}$ & SPME & $100 \mu \mathrm{m}$ PDMS & GC-MS & [62] \\
\hline $\begin{array}{l}\text { Pinus ponderosa Douglas ex } \\
\text { C.Lawson }\end{array}$ & $\begin{array}{l}\text { Sesquiterpenes, methyl } \\
\text { chavicol }\end{array}$ & $\begin{array}{l}\text { D-HS enclosure } \\
\text { coupled with SPME }\end{array}$ & $65 \mu \mathrm{m}, \mathrm{PDMS} / \mathrm{DVB}$ & GC-MS/PTR-MS & [54] \\
\hline $\begin{array}{l}\text { Pinus sabiniana Douglas, } \\
\text { Pinus ponderosa Douglas ex } \\
\text { C.Lawson }\end{array}$ & Sesquiterpenes & $\begin{array}{l}\text { D-HS enclosure } \\
\text { coupled with SPME }\end{array}$ & $100 \mu \mathrm{m}$ PDMS & GC-FID/MS & [21] \\
\hline Pinus sylvestris L. & Monoterpenes & $\begin{array}{l}\text { D-HS enclosure } \\
\text { coupled with SPME }\end{array}$ & $65 \mu \mathrm{m}, \mathrm{PDMS} / \mathrm{DVB}$ & GC-MS & [55] \\
\hline Pinus sylvestris L. & Monoterpenes, aldehydes & $\begin{array}{l}\text { D-HS enclosure } \\
\text { coupled with SPME }\end{array}$ & $65 \mu \mathrm{m}, \mathrm{PDMS} / \mathrm{DVB}$ & GC-MS/PTR-MS & [23] \\
\hline Quercus alba L. & Isoprene & D-HS enclosure & I & GC-FID & {$[24]$} \\
\hline $\begin{array}{l}\text { Taraxacum sect. ruderalia, } \\
\text { Kirschner, Øllgaard et } \\
\text { Štěpánek }\end{array}$ & $\begin{array}{l}\text { Terpenes, ketones, } \\
\text { aldehydes }\end{array}$ & S-HS & PDMS & GC-MS & [78] \\
\hline $\begin{array}{l}\text { Temnadenia odorifera (Vell.) } \\
\text { J.F.Morales }\end{array}$ & $\begin{array}{l}\text { Terpenes, benzenoids, } \\
\text { phenylpropanoids }\end{array}$ & D-HS enclosure & $\begin{array}{l}3 \text { mg Porapak Q } \\
80 / 100 \text { mesh }\end{array}$ & GC-MS & [44] \\
\hline Viola etrusca Erben & $\begin{array}{l}\text { Terpenes, alcohols, } \\
\text { aldehydes, esters }\end{array}$ & SPME & $100 \mu \mathrm{m}$ PDMS & GC-MS & [61] \\
\hline
\end{tabular}

NA, data not available 
Table 2. In-vivo studies of volatiles emitted by plants submitted to different stress and environmental factors: plant(s) and analytes investigated, stress source, sampling techniques, sorbent devices and analytical techniques applied.

\begin{tabular}{|c|c|c|c|c|c|c|}
\hline Plant(s) & Analytes & $\begin{array}{l}\text { Stressor / } \\
\text { Environmental factor }\end{array}$ & $\begin{array}{l}\text { Sampling } \\
\text { technique }\end{array}$ & Sorbent device & $\begin{array}{l}\text { Analytical } \\
\text { technique }\end{array}$ & Ref. \\
\hline Abies fraseri (Pursh) Poir. & Terpenes & Mechanical damage & SPME & $100 \mu \mathrm{m}$ PDMS & GC-MS & [60] \\
\hline $\begin{array}{l}\text { Achillea collina Becker ex } \\
\text { Rchb, Pisum sativum L., } \\
\text { Prunus persica (L.) Batsch }\end{array}$ & Terpenes, alcohols, esters & $\begin{array}{l}\text { Insect feeding, } \\
\text { Mechanical damage, } \\
\text { Chemical }\end{array}$ & SPME & $\begin{array}{l}50 / 30 \mu \mathrm{m} \\
\mathrm{PDMS} / \mathrm{DVB} / \mathrm{CAR}\end{array}$ & GC-MS & [77] \\
\hline $\begin{array}{l}\text { Arabidopsis thaliana (L.) } \\
\text { Heynh. }\end{array}$ & Terpenes, apocarotenoids & Gene overexpression & $\begin{array}{l}\text { D-HS } \\
\text { enclosure }\end{array}$ & Poropak & GC-MS & [50] \\
\hline $\begin{array}{l}\text { Begonia semperflorens Link } \\
\text { \& Otto }\end{array}$ & Terpenes & $\begin{array}{l}\text { Light, Mechanical } \\
\text { damage }\end{array}$ & $\begin{array}{l}\text { D-HS } \\
\text { enclosure }\end{array}$ & / & GC-MS/SESI-MS ${ }^{a}$ & [49] \\
\hline $\begin{array}{l}\text { Betula nana L., Salix } \\
\text { arctophila Cockerell, Salix } \\
\text { glauca L., Empetrum } \\
\text { hermaphroditum Hagerup }\end{array}$ & Terpenes, isoprene, esters & Light, Temperature & $\begin{array}{l}\text { D-HS } \\
\text { enclosure }\end{array}$ & $\begin{array}{l}\text { 150/200 mg Tenax } \\
\text { TA/Carbograph }\end{array}$ & GC-MS & [43] \\
\hline Brassica juncea (L.) Czern. & Selenium, sulfur species & $\begin{array}{l}\text { Micro/macro-nutrient } \\
\text { composition }\end{array}$ & SPME & $75 \mu \mathrm{M}, \mathrm{PDMS} / \mathrm{CAR}$ & GC- ICPMS ${ }^{b}$ & [68] \\
\hline Brassica nigra (L.) K.Koch & $\begin{array}{l}\text { Sulfur compounds, } \\
\text { glucosinolate breakdown } \\
\text { products }\end{array}$ & Insect feeding & $\begin{array}{l}\text { D-HS } \\
\text { enclosure }\end{array}$ & $\begin{array}{l}\text { 150/150 mg Tenax } \\
\text { TA/Carbopack B }\end{array}$ & GC-MS/PTR-MS & [47] \\
\hline
\end{tabular}


Brassica oleracea L. var. acephala + Pieris brassicae

(L.) larvae

Calocedrus macrolepis Kurz

Centaurea spp.

Citrus spp.

Cryptomeria japonica

(Thunb. ex L.f.) D.Don

Dionaea muscipula J.Ellis

Diplotaxis erucoides (L.) DC.

Eucalyptus citriodora Hook.

Fagus sylvatica L.

Fagus sylvatica L.

Gossypium hirsutum L.
Terpenes, alcohols, aldehydes, ketones

Insect feeding

Terpenes

Sesquiterpenes

Terpenes

Terpenes, esters

Terpenes, benzenoids, alcohols, esters

Light

Mechanical damage

CLas ${ }^{\mathrm{c}}$ pathogen

Light, Temperature

Micro/macro-nutrient

composition

Inset feeding

ethyl acetate

Mechanical damage

Light, Temperature

Monoterpenes

Terpenes

Light, Temperature

Insect feeding
SPME

$65 \mu \mathrm{m}, \mathrm{PDMS} / \mathrm{DVB} \quad$ GC-MS

SPME $\quad 65 \mu \mathrm{m}$, PDMS/DVB GC-FID/MS

SPME $\quad 100 \mu \mathrm{m}$ PDMS $\quad$ GC-MS

D-HS Carbopack X/B GC-DMS

enclosure

$\begin{array}{ll}\text { D-HS } & 200 \mathrm{mg} \text { Tenax TA } \\ \text { enclosure } & 60 / 80 \text { mesh }\end{array}$

GC-MS/PTR-MS

D-HS PDMS

enclosure

D-HS /

PTR-MS

enclosure

SPME $\quad 65 \mu \mathrm{m}, \mathrm{PDMS} / \mathrm{DVB} \quad$ GC-MS

GC-FID/MS

$\begin{array}{ll}\text { D-HS } & \text { Tenax TA/ } \\ \text { enclosure } & \text { Carbotrap,Carbograp }\end{array}$

h $1 / 5$

D-HS

130/130 mg

enclosure

Carbograph 1/5

GC-FID/MS

50 mg SuperQ

GC-MS

enclosure 
Hedera helix L., Jasminum polyanthum Franch.,

Lycopersicon esculentum

Mill.

Lycopersicon esculentum

Mill., Artemisia annuifolia L.,

Portulaca oleracea L.

Mediterranean spp.

Mentha spp.

Phaseolus lunatus L.

Phragmites australis (Cav.)

Trin. ex Steud.

Picea abies (L.) H.Karst.

Pinus ponderosa Douglas ex C.Lawson, Arctostaphylos spp., Ceanothus cordulatus Kellogg
Terpenes, benzyl acetate

Light, Insect feeding, Mechanical damage

Chemical

1,8-cineole

Isoprene, monoterpenes

Light, Temperature

Insect feeding

1,8-cineole, monoterpenes,

phenylpropanoids

$\mathrm{C}_{6}$ compounds

Terpenes, aldehydes, alcohols, acetates

\section{MTBE $^{\mathrm{e}}$}

Terpenes

Sesquiterpenes, methyl chavicol

Light, $\mathrm{O}_{3}$ emission

Insect feeding,

Mechanical damage

Chemical

Insect feeding,

Chemical

Light, Temperature

\section{D-HS}

enclosure

300 mg PDMS

GC-MS

(

DI-SPME

$100 \mu \mathrm{m}$ PDMS

GC-MS

[82]

$\begin{array}{lll}\begin{array}{l}\text { D-HS } \\ \text { enclosure }\end{array} & \begin{array}{l}\text { Multilayer } \\ \text { cartridges/Cryotrap }\end{array} & \text { GC-FID/MS } \\ \text { SPME } & \begin{array}{l}50 / 30 \mu \mathrm{m} \\ \text { PDMS/DVB/CAR }\end{array} & \text { GC } \times \text { GC-MS } \\ & \end{array}$

D-HS

enclosure

DC-STE

33 mg PDMS

GC-MS

DI-SPME

$85 \mu \mathrm{m}$ PDMS/CAR

GC-MS

SPME

$65 \mu \mathrm{m}, \mathrm{PDMS} / \mathrm{DVB}$

GC-MS

D-HS

enclosure

$65 \mu \mathrm{m}, \mathrm{PDMS} / \mathrm{DVB}$

GC-FID/MS/PTRMS 


\begin{tabular}{|c|c|c|c|c|c|}
\hline Pinus spp. & $\begin{array}{l}\text { Sesquiterpenes, } \\
\text { monoterpenes }\end{array}$ & Light, Temperature & $\begin{array}{l}\text { D-HS } \\
\text { enclosure }\end{array}$ & Tenax GR & GC-FID/MS \\
\hline Pinus sylvestris L. & $\begin{array}{l}\text { Monoterpenes, } \\
\text { sesquiterpenes }\end{array}$ & Light, Temperature & $\begin{array}{l}\text { D-HS } \\
\text { enclosure }\end{array}$ & $\begin{array}{l}\text { Tenax TA, } \\
\text { Carbopack B }\end{array}$ & GC-MS \\
\hline Pinus taeda $\mathrm{L}$. & $\begin{array}{l}\text { Monoterpenes, } \\
\text { sesquiterpenes }\end{array}$ & Light, Temperature & $\begin{array}{l}\text { D-HS } \\
\text { enclosure }\end{array}$ & $\begin{array}{l}\text { Tenax TA/GR, } \\
\text { Carbotrap C }\end{array}$ & GC-FID/MS \\
\hline $\begin{array}{l}\text { Populus x canescens (Aiton) } \\
\text { Sm. }\end{array}$ & $\begin{array}{l}\text { Acetaldehyde, isoprene, } \\
\mathrm{C}_{6} \text { compounds }\end{array}$ & $\begin{array}{l}\text { Light, Anaerobic } \\
\text { condition }\end{array}$ & $\begin{array}{l}\text { D-HS } \\
\text { enclosure }\end{array}$ & / & PTR-MS \\
\hline $\begin{array}{l}\text { Pseudotsuga menziesii } \\
\text { (Mirb.) Franco, Tsuga } \\
\text { heterophylla (Raf.) Sarg. }\end{array}$ & Monoterpenes & Light, Temperature & $\begin{array}{l}\text { D-HS } \\
\text { enclosure }\end{array}$ & Cryotrap & GC-FID \\
\hline Quercus coccifera $\mathrm{L}$. & Terpenes & Light, Temperature & $\begin{array}{l}\text { D-HS } \\
\text { enclosure }\end{array}$ & $200 \mathrm{mg}$ Tenax TA & GC-FID/MS \\
\hline Quercus ilex L. & $\begin{array}{l}\text { Monoterpenes, } \mathrm{MeOH} \text {, } \\
\text { EtOH, acetaldehyde }\end{array}$ & Light, Flooding & $\begin{array}{l}\text { D-HS } \\
\text { enclosure }\end{array}$ & / & PTR-MS \\
\hline Quercus macrocarpa Michx. & Isoprene & Temperature & $\begin{array}{l}\text { D-HS } \\
\text { enclosure }\end{array}$ & $\begin{array}{l}\text { 60/80 mesh glass } \\
\text { beads (cryotrap) }\end{array}$ & GC-FID \\
\hline $\begin{array}{l}\text { Raphanus sativus L., } \\
\text { Brassica juncea (L.) Czern. }\end{array}$ & Se species & $\begin{array}{l}\text { Micro/macro-nutrient } \\
\text { composition }\end{array}$ & SPME & $75 \mu \mathrm{m}, \mathrm{PDMS} / \mathrm{CAR}$ & GC-MS \\
\hline Rice plant (spp. NA) & Aldehydes, EtOH & Anaerobic conditions & $\begin{array}{l}\text { D-HS } \\
\text { enclosure }\end{array}$ & / & $\begin{array}{l}\text { PTR-MS/CO laser- } \\
\text { based detector }\end{array}$ \\
\hline
\end{tabular}




\begin{tabular}{|c|c|c|c|c|c|c|}
\hline Solanum lycopersicum L. & Terpenes & $\begin{array}{l}\text { Insect feeding, } \\
\text { Chemical }\end{array}$ & DC-SBSE & PDMS & GC-MS & [86] \\
\hline Succisa pratensis Moench & $\begin{array}{l}\text { Acetaldehydes, EtOH, } \\
\text { terpenes, } \mathrm{MeOH}\end{array}$ & Insect feeding & $\begin{array}{l}\text { D-HS } \\
\text { enclosure }\end{array}$ & $\begin{array}{l}\text { 300/200/125 mg } \\
\text { Carbotrap } \\
\text { B/C/Carbosieve S III }\end{array}$ & GC-MS/PTR-MS & [30] \\
\hline Tea plant (spp. NA) & $\begin{array}{l}\text { Terpenes, alcohols, } \\
\text { acetaldehyde }\end{array}$ & $\begin{array}{l}\text { Insect feeding, } \\
\text { Chemical }\end{array}$ & DC-SBSE & PDMS & GC-MS & [12] \\
\hline
\end{tabular}

NA, data not available acetaldehyde Chemical

${ }^{\text {a }}$ Electrospray ionization source coupled to a mass analyser

${ }^{\mathrm{b}}$ Inductively coupled plasma mass spectrometry

${ }^{\mathrm{c}}$ Candidatus Liberibacter asiaticus

${ }^{\mathrm{d}}$ Differential mobility spectrometry

${ }^{\mathrm{e}}$ Methyl-tert-butyl ether 